\title{
Las encuestas del Centro de Estudios Públicos en la coyuntura plebiscitaria, 1987- 1988: surgimiento, crítica y valoración de un insumo político*
}

\author{
The surveys of the Center for Public Studies in the plebiscitary situation, 1987-1988: \\ emergence, criticism and evaluation of a political input
}

Maximiliano Jara**

\section{RESUMEN}

El artículo analiza los efectos de los estudios de opinión realizados por el Centro de Estudios Públicos (CEP) en la prensa tradicional, camino al plebiscito de 1988, durante los últimos años de la dictadura de Augusto Pinochet. Así, se propone que: primero, fue gracias a las encuestas que el Centro incrementó la visibilidad pública de sus diagnósticos y, en segundo lugar, pese a que el Centro era una iniciativa de civiles que apoyaba al régimen, la institución evitó apoyar activamente a Pinochet con sus encuestas en la coyuntura plebiscitaria, a contrasentido de otras instituciones del sector. Como fuentes se usó el archivo del CEP, entrevistas con actores y bibliografía secundaria.

Palabras claves: think tanks, encuestas, Centro de Estudios Públicos, plebiscito de 1988, derecha chilena.

\section{ABSTRACT}

The article analyses the effects of the polls made by the Centro de Estudios Públicos (CEP) on the traditional press, on the road to the plebiscite of 1988, during the last years of Pinochet's dictatorship. Thus, it proposes that: first, it was thanks to the polls that the CEP increased the public visibility of its diagnostics and, in the second place, despite that this institution was an initiative of civilians that supported the regime, the CEP avoided actively supporting Pinochet with its polls during those years, in contrast to other institutions that were part of the same sector. The CEP'S archive and interviews with actors of those years were used as sources.

Keywords: think tanks, polls, Centro de Estudios Públicos, plebiscite of 1988, Chilean right-wing.

Recibido: septiembre 2019

Aceptado: diciembre 2019

\footnotetext{
* Este artículo es parte de mi investigación de tesis de magíster titulada "Centro de Estudios Públicos (CEP). Ideas y acción política: pensando la nueva democracia (1980-2010)", desarrollada en la Pontificia Universidad Católica de Chile.

** Licenciado en Historia y estudiante del Magíster en Historia por la Pontificia Universidad Católica de Chile. Email: mdjara@uc.cl.
} 


\section{Introducción}

En la historia reciente de Chile las encuestas de opinión han logrado marcar la agenda del debate público. Mes a mes, estas han acrecentado o perjudicado la popularidad de los políticos, puesto temas de interés para la ciudadanía -tales como el sistema de pensiones, seguridad o salud- y contribuido a perfilar a posibles candidatos presidenciales. ${ }^{1}$ Todo esto gracias a una legitimidad técnica que las encuestadoras apelan $-y$ necesitan tener- para influir en la sociedad, utilizando de este modo una serie de metodologías que sustenten lo científico de sus trabajos, con el objeto de proveer diagnósticos con base e intentar despejar la duda que sus resultados puedan entregar. No obstante, es innegable que en nuestro presente las encuestas y las instituciones que las realizan se han posicionado como actores políticos sumamente influyentes de la democracia chilena inaugurada en 1990.

Entre las encuestas políticas más valoradas del país desde el retorno a la democracia se encuentran las realizadas por el Centro de Estudios Públicos, un think tank liberal fundado en 1980 como fruto de la alianza entre los principales asesores económicos de la dictadura, los grupos empresariales más importantes de Chile en ese entonces y el apoyo de una red de académicos liberales alrededor del mundo. ${ }^{2}$ Ahora bien, como se verá, las encuestas CEP no siempre fueron bien consideradas en el espectro político, ni siquiera en la totalidad de las derechas del país, ya fuesen la Junta Militar, los partidos del sector ${ }^{3}$ o los medios de comunicación. ${ }^{4}$ Su trabajo durante sus primeros años no tuvo el peso que tendría posteriormente en democracia, e incluso hubo ocasiones en que era criticado con fuerza, al tiempo que sus insumos no eran utilizados por la centro izquierda y, en caso de contemplarlos, existía cierta desconfianza hacia ellos, ya que provenían de una institución comprometida con la proyección del ideario económico del régimen militar.

Por lo anterior, es necesario analizar cómo fue que las encuestas CEP fueron posicionándose como un insumo útil para la comunidad política que conduciría el proceso de redemocratización. Para estos efectos, planteamos que es necesario remontarse a los orígenes de estos estudios de opinión y develar su impacto en la coyuntura plebiscitaria de 1988, la cual

\footnotetext{
1 Huneeus, Carlos. 2009. "Las encuestas de opinión pública en las nuevas democracias de América Latina”, La sociología en sus escenarios, N 9, pp. 9-29; Dockendorff, Andrés. 2010. "El rol de las encuestas en las elecciones de 2005. Selección de candidatos presidenciales en Chile", Revista Enfoques. Ciencia Política y Administración pública, vol. VIII, N 13, pp. 159-180.

2 Jara Barrera, Maximiliano. 2019. "El origen del Centro de Estudios Públicos: importando el liberalismo para una transición ideológica, 1980-1982" Historia 396, n 1, 2019, pp. 225-253.

3 Pablo Rubio Apiolaza sintetiza la participación de ambos partidos en la campaña. Ver Rubio Apiolaza, Pablo. 2012. Los civiles de Pinochet. La derecha en el régimen militar chileno, 1983-1990, Santiago, DIBAM, 2012, pp. 265-283

${ }^{4}$ La derecha chilena es más amplia que una noción partidista, ya que se ve presente en múltiples ámbitos de la esfera civil y empresarial. Véase Correa Sutil, Sofía. 2011. Con las riendas del poder. La derecha chilena en el siglo XX, Santiago, Debolsillo.
} 
se constituyó en una verdadera prueba de fuego para las encuestadoras nacionales. Entonces, la gran mayoría de los sondeos vinculados a la derecha avizoraban la victoria de la opción sí por un amplio margen, minimizando las posibilidades que la oposición tenía. Solo los estudios ligados a la oposición, entre los que destacó el Centro de Estudios de la Realidad Contemporánea (CERC), y lo hecho por el Centro de Estudios Públicos preveían la victoria del NO. De este modo, la investigación sostiene que las encuestas del Centro si bien provenían del sector ideológicamente más afín al sistema económico del régimen, no fueron un insumo político valorado para el sector al entregar datos perjudiciales para las aspiraciones del oficialismo y sus aliados, al contrario de lo realizado por otras encuestadoras vinculadas a la derecha. Es decir, sugerimos que fue el desempeño del Centro camino al plebiscito de 1988 lo que le entregó la legitimidad necesaria a la institución para transformarse en una caja de herramientas común del espectro político que formaría la nueva democracia chilena.

No solo es importante analizar al Centro de Estudios Públicos por la relevancia actual que tiene en el país, sino porque en la historia de esta institución han confluido una serie de procesos ideológicos, políticos, económicos y sociales que han dado forma a la nueva democracia. El CEP ha sido parte, ya sea como un actor o espacio de la política, de una serie de elementos claves para entender la formación de una comunidad que lideró la transición a la democracia en Chile y que dio forma al nuevo ciclo democrático del país.

Estudiar las encuestas CEP en la coyuntura plebiscitaria de 1988 implica vincular estos insumos con una etapa clave del desarrollo político nacional: el paso de un autoritarismo a un sistema democrático. En ese sentido, este estudio de caso permitirá visualizar la necesidad política que originó la creación de un instrumento de este tipo para el Centro, debido a la incertidumbre que los defensores del libre mercado tenían con respecto a la valoración que la población poseía con respecto a la obra del régimen. Servirá también para comprender cómo las encuestas se vincularon con los medios de comunicación y generaron un conocimiento que cuestionó el desarrollo político reciente del país. Y, por último, será útil para aproximarnos a las reacciones de los diferentes grupos de poder de la derecha -tales como el régimen militar, medios de comunicación y gran empresariado-, al uso de estos instrumentos en momentos donde el destino de su proyecto estaba en juego.

Realizar esto a través del estudio de las encuestas no es algo baladí. Hasta ahora, ha sido la Ciencia Política y la Sociología las que preferentemente las han estudiado. En Chile, las encuestas han sido parte de la producción académica principalmente por dos motivos. Primero, al ser usadas como una fuente para analizar los cambios políticos y sociales del país. Y, por otro lado, para analizar el impacto público que este insumo ha tenido en la opinión pública. Los primeros precursores en estudiarlas en Chile fueron José Joaquín Brunner, Carlos Huneeus, J. 
Paley, y Guillermo Sunkel, ${ }^{5}$ los que, a excepción de Paley, se interesaron en vincular las encuestas con el plano de "la" política, concentrándose especialmente en el período final de la dictadura e inicios de la década de $1990 .{ }^{6}$

Tanto Brunner, Huneeus y Sunkel se enfocaron principalmente en dos cosas: primero, el interés por comprender la sociedad durante la dictadura y, segundo, el uso del saber generado por los think tanks de oposición a través de sus encuestas en la campaña del NO, en el plebiscito de 1988. Estos trabajos se enfocaron en los tomadores de decisiones de la oposición, antes que analizar el cómo una encuesta de opinión se inserta en el debate público, levantando diagnósticos y generando discusión. Al enfocarse solo en la centroizquierda chilena, no se comprende el rol que jugaron los estudios de opinión realizados por la derecha camino al plebiscito de 1988. Dos elementos que tampoco han sido respondidos por los análisis generados en el siglo XXI, los que preferentemente se han enfocado en el análisis del rol de las encuestas en la democracia chilena iniciada en 1990 hasta la actualidad. En este último enfoque, ha destacado el análisis de las preferencias políticas del electorado, ${ }^{7}$ la valoración de los partidos políticos, ${ }^{8}$ la percepción de seguridad ciudadana, ${ }^{9}$ entre otras. Por aquello, esta investigación prefiere volver a la década de 1980 y analizar el impacto público que tuvieron las encuestas CEP camino al plebiscito de 1988.

${ }^{5}$ Brunner, José Joaquín y Sunkel, Guillermo. 1993. Conocimiento, sociedad y política, Santiago, Libros FLACSO; Sunkel, Guillermo. Diciembre 1989. "Las encuestas de opinión pública: entre el saber y el poder", Documento de Trabajo N 439, FLACSO, Santiago; Sunkel, Guillermo. Marzo 1992. "Los usos políticos de las encuestas", Documento de trabajo $N^{\circ} 18$, FLACSO, Serie Educación y Cultura, Santiago; Huneeus, op. cit., pp. 9-30; Paley, Julia. 2001. “Making Democracy Count: Opinion Polls and Market Surveys in the Chilean Political Transition", Cultural Anthropology, vol. 16, $\mathrm{N}^{\circ} 2$, pp. 135-164.

6 Pierre Rosanvallon diferencia "Io político" de "la política". El primero tendría por objeto "seguir el hilo de las experiencias y de tanteos, de los conflictos y las controversias, a través de los cuales la polis ha buscado encontrar su forma legítima". Mientras tanto, la segunda sería aquella interesada en "la reconstrucción de la sucesión cronológica de los acontecimientos, analiza el funcionamiento de las instituciones, desmenuza los mecanismos de toma de decisiones públicas, interpreta el resultado de las elecciones, echa luz sobre las razones de los actores y el sistema de sus interacciones, describe los rituales y los símbolos de la vida". Así, Rosanvallon pone énfasis en la forma de la legitimidad de la política, véase Rosanvallon, P. 2003. Por una historia conceptual de lo político, Buenos Aires, Fondo de Cultura Económica, pp. 26-30.

${ }^{7}$ Contreras, Gonzalo y Navia, Patricio. 2013. “Diferencias generacionales en la participación electoral en Chile, 19882010", en Revista de Ciencia Política, vol. 33, N², pp. 419-441; Barrueto, Felipe y Navia, Patricio. 2015. "Evolución de las preferencias políticas y de políticas públicas entre el sector popular y el resto de la sociedad chilena entre 1990 y 2012", en Perfiles latinoamericanos, vol. 23, º 46, pp. 61-89; Segovia, Carolina. 2009. “¿Crisis de la política? Percepciones y valoraciones de los partidos", en Rodrigo Cordero, La sociedad de la opinión. Reflexiones sobre encuestas y cambio político en democracia, Santiago, Ediciones Universidad Diego Portales, pp. 197-224.

${ }^{8}$ Segovia, Carolina, op. cit.

9 Dammere, Lucía. 2009. “¿¿Falsa alarma? Temor, crimen y opinión pública en Chile, en Cordero (ed.), op. cit., pp. 225-250. 
De ese modo, esta investigación no solo es importante para estudiar al Centro de Estudios Públicos y la construcción de su legitimidad pública, sino que también constituye un aporte al análisis de la coyuntura plebiscitaria desarrollada en Chile en el año 1988. Un momento en el cual el uso del saber científico demostró conllevar una voluntad de poder político en el momento. Es decir, al tiempo que se buscaba proveer de diagnósticos e información útil a los tomadores de decisiones, las encuestadoras -como el CEP-, buscaban hacer que su conocimiento pudiera llegar al régimen, los partidos de derecha e izquierda, el gran empresariado y la academia. A fin de cuentas, lo que instituciones como el CEP buscaban era ser proveedores de diagnósticos y soluciones para las elites de entonces.

A lo largo de este artículo estará presente la pregunta de si las encuestas podrían haberse traducido en algún tipo de influencia de parte del think tank estudiado en el espacio público. Evaluar esto último en una institución como el CEP es una labor sumamente complicada. El politólogo Donald Abelson sugiere que es preferible dejar de lado la noción de una "influencia directa", en donde una institución tiene la capacidad para cambiar la acción de otro organismo sin la participación de más actores, por lo complejo de demostrar esa linealidad. En cambio, sería preferible usar la idea de una "influencia holística", es decir, estudiar cómo la producción cultural de una institución participa y hace reaccionar a un determinado contexto en el cual está inserto el organismo a influir. En ese sentido, para comprender la influencia de las encuestas CEP sería apropiado comprender cómo estas se insertaron en su tiempo, lo que constituye el principal objetivo de la investigación.

Metodológicamente, nos es necesario realizar un doble trabajo: uno cuantitativo y otro cualitativo. Así, hemos cuantificado el número de menciones sobre el CEP en la prensa del período estudiado y, por otro lado, analizado estas noticias para comprender cómo fue recibida entonces en la prensa de la época. Esto mostrará cómo se valoraban o no los diagnósticos emanados desde el CEP en el espacio público a lo largo de la década de 1980 y, en específico, durante la coyuntura plebiscitaria. No obstante, es necesario advertir que este trabajo no busca dimensionar la influencia del Centro, ni las distintas ideas o la acción política que la institución llevó a cabo durante toda la década de 1980, algo que supera los límites de esta investigación. ${ }^{10}$ Sino más bien tiene por interés entender la recepción que tuvieron las encuesto del Centro en los medios de comunicación en la coyuntura crítica como lo fue el plebiscito de 1988.

Para llevar esto a cabo, este trabajo se ha centrado principalmente en el análisis de fuentes escritas, ya sean propias del Centro de Estudios Públicos o medios de comunicación de la época, y la bibliografía secundaria pertinente para contextualizar el período. Así, se utilizaron actas del

\footnotetext{
${ }^{10}$ Aquellos elementos son desarrollados con mayor profundidad en mi investigación de Magíster desarrollada en la Pontificia Universidad Católica de Chile titulada "Centro de Estudios Públicos. Ideas y acción política, pensar la transición a una nueva democracia", actualmente en evaluación.
} 
consejo directivo de la institución, como también su producción cultural. Además, se realizaron una serie de entrevistas a miembros del CEP de ese entonces, tales como su director, Arturo Fontaine Talavera, el académico Óscar Godoy y el director de ADIMARK, Roberto Méndez. A lo que se incluyó el uso del archivo del CEP.

\section{Una aproximación al impacto público de las encuestas CEP en la prensa tradicional}

Para comprender el impacto público de las encuestas CEP en el período estudiado, es necesario cuantificar el número de menciones en la prensa de la época. Para realizar aquello, hemos utilizado el archivo documental de Centro de Estudios Públicos, el cual contiene la colección más completa de notas de este tipo sobre la institución. Elaborado en la década de 1980, este acervo documentó prácticamente todas las notas de prensa existentes sobre la institución, en los más diversos medios de Chile y el extranjero. Aunque en principio abarcaría un importante espectro de noticias, podrían quedar notas de prensa que no se hayan integrado. No obstante si ese fuese el caso, este archivo merece valorarse porque al ser creado bajo los criterios de interés del CEP en la época, es reflejo del circuito comunicacional en el que estaba inscrito el Centro, a saber: mayormente la prensa tradicional de circulación nacional, comprometida de alguna $u$ otra forma con -al menos- aspectos del proyecto del régimen militar, como se aprecia en la tabla $n^{\circ} 1$. Aunque sin desmerecer una leve presencia en medios de comunicación de oposición, tales como La Época o la revista Hoy.

Tabla $\mathrm{n}^{\circ}$ 1: número de menciones sobre el CEP entre junio de 1980 y octubre de 1988

\begin{tabular}{|c|c|}
\hline El Mercurio & 289 \\
\hline La Segunda & 132 \\
\hline La Tercera & 35 \\
\hline Qué Pasa & 31 \\
\hline La Época & 30 \\
\hline Las Últimas Noticias & 23 \\
\hline Estrategia & 14 \\
\hline Ercilla & 13 \\
\hline Economía y Sociedad & 10 \\
\hline Hoy & 7 \\
\hline Otros & 27 \\
\hline Total & 611 \\
\hline
\end{tabular}

Fuente: elaboración propia a partir de revisión de Archivo CEP.

En este sentido, según la tabla $n^{\circ} 1$ existió especial atención en los medios del grupo Edwards, principalmente en El Mercurio y La Segunda, medios altamente simpatizantes con el proyecto de libre mercado y dirigidos especialmente a la élite nacional. Mientras que otros medios cercanos a esta opción, tal como La Tercera, Las Últimas Noticias (también del grupo 
Edwards, pero enfocado en noticias policiales) Estrategia, Qué Pasa o La Nación, si bien mostraba interés no contaba con números abultados, excepto tal vez por La Tercera. Por otro lado, se nota escasa visualización en el CEP en revistas de oposición como Análisis, HOY, Ercilla o APSI; aunque sí se encuentra mayor atención en La Época, medio de comunicación cercano a la Democracia Cristiana. Por lo tanto, podríamos decir que el CEP si bien recibió atención de diferentes medios a lo largo de la década de 1980, su producción cultural era tratada como insumo político principalmente en medios relacionados al grupo Edwards.

A lo anterior, también es necesario explicar que en el período estudiado existió un sesgo comunicacional hacia la derecha, ya fuese por las políticas comunicacionales del régimen, la moderación (especie de autocensura) o, principalmente, por la coincidencia ideológica que los grandes conglomerados que controlaban la prensa tenían con el proyecto desarrollado en esos años. ${ }^{11}$ Es decir, el acervo documental utilizado en esta investigación, da mayormente cuenta de la recepción y crítica que el campo comunicacional de las derechas tuvo de las encuestas, antes que una representación de todo el espectro político. Un hecho importante, ya que explica por qué finalmente en la prensa analizada existe una línea editorial cercana políticamente al CEP antes que una visión crítica de su trabajo, no obstante si se hayan detectado voces contrarias. Es más, incluso al profundizar en medios de comunicación como Hoy, APSI, Fortín Mapocho o La Época durante el período estudiado, con el objeto de confrontar un posible sesgo del archivo, las menciones realizadas por aquellos medios del Centro fueron escasas, lo que hace pensar que la institución no era un referente de aquel circuito comunicacional.

Entendiendo que existió una importante cobertura de prensa sobre la producción cultural del Centro a lo largo de la década, algo que incluyó seminarios, publicaciones, entrevistas y encuestas, es necesario visualizar qué diferencia hicieron estas últimas en el impacto público de la institución. Por ello, cuantificamos las notas de prensa en forma mensual durante todo el decenio de 1980, comenzando desde la fundación del Centro en junio de 1980. Gracias a lo anterior, se puede apreciar en el gráfico $n^{\circ} 1$ que fue gracias a las encuestas de opinión creadas en 1987 que el CEP logró mayor repercusión mediática, ya que, a partir de la encuesta de octubre de aquel año, los peaks que siguieron coincidieron con la liberación de los mentados estudios de opinión más que por una valoración distinta del resto de su producción cultural. Ahora bien, es necesario comprender qué tipo de referencias se hacían a la encuesta del Centro durante sus primeros años.

\footnotetext{
${ }^{11}$ Sobre la concentración de los medios de comunicación véase Mönckeberg, María Olivia. 2013. Los magnates de la prensa. Concentración de los medios de comunicación en Chile, Santiago, Debolsillo, capítulo II.
} 
Gráfico n¹: Apariciones Centro Estudios Públicos en prensa nacional junio 1980- junio 1990

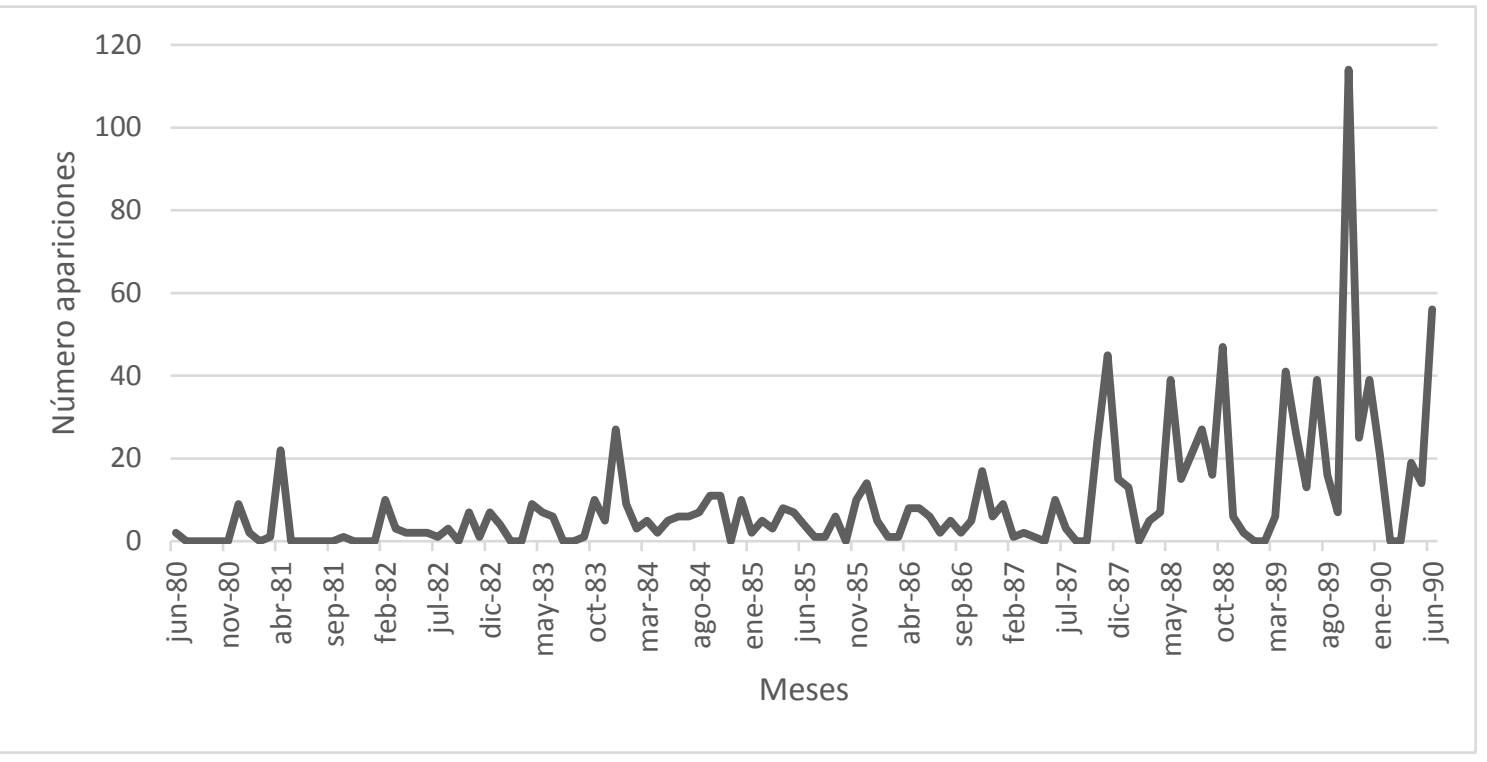

Fuente: elaboración propia a partir de revisión de archivo CEP.

\section{El nuevo poder de las encuestas: sociedad y política}

Un nuevo factor influyó en la política chilena de la segunda mitad de la década de 1980: las encuestas y estudios de opinión. Estas tenían una "prehistoria" en Chile que se remontaba a la primera mitad del siglo XX, cuando instituciones universitarias, medios de comunicación y la Iglesia católica utilizaban sondeos de opinión, aunque sin las herramientas metodológicas y el impacto político que alcanzarían más tarde. ${ }^{12}$ El inicio formal de la industria de las encuestas en Chile puede rastrearse hasta 1957, cuando el sociólogo Eduardo Hamuy realizó una serie de estudios para entender la opinión pública chilena. Estas encuestas tempranamente "alcanzarían interés y uso político", ya sea por las elecciones presidenciales de 1958, 1964 y 1970, o por el asesoramiento a gobiernos como el de Eduardo Frei Montalva. ${ }^{13}$ El trabajo de Hamuy es importante para conocer la sociedad previa al Golpe de Estado de 1973, lo que ya se ha realizado en algunos trabajos. ${ }^{14}$

Fue el Centro de Estudios Económicos, fundado por el grupo Edwards, el primero en destacar con las encuestas políticas que suministraba información a la campaña de Jorge

\footnotetext{
${ }^{12}$ Cordero, Rodrigo. 2009. "Dígalo con números: la industria de la opinión pública en Chile”, en Cordero (ed.), op. cit., pp. 72 y 75 .

13 Ibid., p. 76.

14 Navia, Patricio y Osorio, Rodrigo. 2015. "Las encuestas de opinión pública en Chile antes de 1973", en Latin American Research Review, 30, pp. 117-139.
} 
Alessandri en $1970 .^{15}$ Estas eran utilizadas para planificar la campaña como también para evaluar las coyunturas políticas. Durante toda la campaña presidencial de 1970, Alessandri y la derecha creían, en parte en base a estos trabajos privados, que iban a ganar las elecciones, y como consecuencia fueron renuentes a aceptar la creación de una segunda vuelta en el sistema político chileno. ${ }^{16}$ Estas encuestas estratégicas eran -en parte- reservadas, con algunas preguntas fuera del escrutinio público, ya que su finalidad era ser utilizadas solo dentro del equipo del candidato.

Con el golpe de Estado en 1973, se produjo un receso político que también afectó la producción de estudios de opinión. Solo existían sondeos que realizaba la junta militar o investigaciones de mercado, unas secretas y las otras sin relevancia partidista. Con el proceso de apertura política en 1983, las encuestas tuvieron un nuevo auge, primero con la empresa Diagnos que era contratada por medios de comunicación tradicionales. ${ }^{17}$ No obstante, "fue con los programas de encuestas nacionales más estructuradas y con respaldo científico por parte de instituciones no comerciales que el estudio de la opinión pública emprendió su despegue en Chile". ${ }^{18}$ Así fue como varias instituciones de investigación social vinculadas a la oposición hicieron uso de ellas, destacando entre 1984 y 1985, el Centro de Estudios del Desarrollo (CED), FLACSO, CERC y el Centro de Estudios Sociales (SUR), todas ellas reservándose el derecho a publicar la totalidad de las preguntas. Pero fue solo "a fines de 1987 y, especialmente en el período pre-plebiscitario, cuando las encuestas de opinión pública adquirieron un rol de primera importancia en el proceso político" ${ }^{19}$ Especialmente porque estas se transformarían en una fuente de información para comprender al Chile intervenido por el proyecto del régimen militar.

En un contexto donde no existía un contacto fluido entre la sociedad y sus partidos políticos a causa del receso político impuesto por la dictadura a partir del 11 de septiembre de 1973, tanto los partidos de oposición como el mismo gobierno necesitaban conocer las aspiraciones de la sociedad chilena. De este modo, las encuestas resultaron fundamentales para superar un período de desconexión entre la esfera política y social. Así se entiende que la oposición democrática tuviese especial interés por este tipo de instrumentos, ya que durante los últimos

\footnotetext{
${ }^{15}$ El trabajo del CESEC es estudiada en forma tangencial en todo el trabajo de Soto, Ángel. 2003. El Mercurio y la Difusión del Pensamiento Político Económico Liberal 1955-1970, Santiago, Centro de Estudios Bicentenario, pp. 4168.

${ }^{16}$ Sobre la campaña de 1970 véase San Francisco, Alejandro. 2005. "La elección presidencial de 1970. Sesenta días que conmovieron a Chile (y al mundo)", en San Francisco, Alejandro y Soto, Ángel (editores), Camino a La Moneda. Las elecciones presidenciales en la historia de Chile, Santiago, Centro de Estudios Bicentenario-Instituto de Historia, Pontificia Universidad Católica de Chile, pp. 333-370.

${ }^{17}$ Sunkel, "Las encuestas de opinión pública...", p. 2.

${ }^{18}$ Cordero, "Dígalo con números...", p. 77.

${ }^{19}$ Sunkel, “Las encuestas de opinión pública...”, p. 2.
} 
años de la década, y a medida que se acercaba la coyuntura plebiscitaria de 1988, los utilizó para elaborar su estrategia política y la creación de la recordada campaña electoral del NO. ${ }^{20}$ Las encuestas fueron uno de los principales elementos donde se apreció la vinculación entre razón técnica y política, ambos actuando interrelacionados a la hora de competir en el espacio público. Fue una alianza que tuvo especial repercusión en el proceso de búsqueda de la democracia, ya que las encuestas sirvieron a las campañas políticas para intentar convencer a la población, en especial al electorado indeciso.

En la década estudiada las encuestas también eran consideradas útiles por la prensa, destacando algunos de ellos que estas servían para:

“(...) percatarse de cuáles son las tendencias de amplios sectores de la opinión pública y así evitar los sesgos y alteraciones que producen ciertas opiniones provenientes de personas, que por el cargo que detentan o la presunta representatividad que poseen, adquieren visos de certeza, a pesar de que no tienen una sustentación científicamente comprobada". ${ }^{21}$

Una interpretación realizada por Las Últimas Noticias que traslucía una confianza en lo técnico por sobre lo político a la hora de representar a la ciudadanía, algo que también se visualizaba en medios como El Mercurio que en junio de 1987 tituló en una ocasión con la frase "Lo que piensan los chilenos", entregándole a la iniciativa del Centro el rol de reflejar el pensamiento de la sociedad. ${ }^{22}$ Aunque esta no era una visión hegemónica, ya que las mismas encuestas eran vistas de diferentes formas. En algunos casos, estas podían ser vistas como mediadores de las opiniones de la sociedad por sobre la política, mientras que para otros esta última debía tener un rol fundamental en aquello. En ese entonces este tipo de instrumentos no hegemonizaron el debate político, como sí lo hicieron luego de las elecciones del plebiscito de 1988. Es decir, la valoración de las encuestas dependía de la cultura política y valoración de las ciencias sociales que cada grupo político tuvo en ese entonces, antes que de una aceptación transversal del instrumento.

\section{La creación de la encuesta CEP}

¿Cómo originó el estudio de opinión del CEP? Arturo Fontaine Talavera, ante la coyuntura plebiscitaria que se veía próxima, quería saber cuál era el país que se enfrentaría en el plebiscito. A causa de la dictadura se había perdido la conexión entre los ciudadanos y la clase dirigente, quedando los primeros alejados de la vida política, y los segundos aislados de una

\footnotetext{
20 Ibid.

21 “Encuestas de opinión pública”. Las Últimas Noticias, Santiago, 15 de junio de 1987.

22 "Encuesta: lo que piensan los santiaguinos", El Mercurio, Santiago, domingo 14 de junio de 1987.
} 
relación fluida con las bases, lo que generó una desconexión entre el político y el ciudadano. ${ }^{23}$ Según cuenta Fontaine, él quería crear un "termómetro común" de la política, más que continuar el modelo de encuesta imperante en la década de 1980: a saber, una encuesta estratégica con preguntas reservadas que, aunque con un trabajo serio detrás, fueran referencia mayormente para su grupo político en particular. ${ }^{24}$ Comentaba que varios cercanos al Centro preferían crear una encuesta únicamente para su sector, al igual que el referente mencionado anteriormente. ${ }^{25}$ En cambio, él pensaba que si lograba crear un termómetro común administrado por el CEP, este haría que la institución se consolidara como un referente transversal del campo político de la nueva democracia. Es decir, según nuestro parecer, lo haría transformarse en un proveedor de diagnósticos de la política. Un hecho que se consolidaría posteriormente en democracia.

De este modo, el director del CEP presentó un proyecto a fines de 1985 al National Endowment for Democracy (NED) titulado "Socio Economic Data for Political Decision Making in Chile: 1986-1987". ${ }^{26}$ La respuesta del presidente del NED, Carl Gershman, recibida el día 18 de febrero de 1986 fue positiva. ${ }^{27}$ La fundación norteamericana aportaría el monto de US\$ 50.000 a la Universidad de Carolina del Sur, institución con la cual el CEP había firmado un convenio para realizar estos sondeos de opinión. ${ }^{28}$ El apoyo externo era indispensable para llevar a puerto esta empresa, pues el CEP no contaba ni con los expertos ni con los fondos para realizar este tipo de estudios.

En la preparación, realización y análisis de la encuesta participaron como coordinadores Alessandra Ducci y Arturo Fontaine Talavera; aportando también en esta labor Enrique Barros, Cristián Eyzaguirre, Juan Andrés Fontaine, David Gallagher, Juan Pablo Illanes, Felipe Larraín, Marisol Navarro y Héctor Kappes. ${ }^{29}$ Mientras en la fase inicial colaboraron Morris Blachman del Institute of International Studies de la Universidad de Carolina del Sur, y Arturo Valenzuela de la Universidad de Duke. La muestra contempló 300 participantes de cada estrato social -alto, medio y bajo-, siendo encuestadas 900 personas en total, y luego de un análisis se desprendió que la opinión recogida un universo representativo de 2.773 .000 de santiaguinos. ${ }^{30}$

\footnotetext{
${ }^{23}$ Entrevista realizada por el autor a Arturo Fontaine Talavera el 25 de mayo de 2018.

24 Ibid.

25 Ibid.

${ }^{26}$ Sesión 1985 de Comité de Consejo, en Santiago 10 de diciembre de 1985, p. 1.

27 Sesión especial del Consejo Directivo $n^{\circ}$ 1/1986, Santiago 25 de marzo de 1986, p. 3.

28 Sesión especial del Consejo Directivo n²/1986, Santiago 17 de junio de 1986, p. 1.

29 "Encuesta: lo que piensan los chilenos", en El Mercurio, Santiago, domingo 14 de julio de 1987, p. C2.

30 Ibid.
} 
La información recabada abordaba temas políticos, económicos, religiosos y sociales, y se difundía públicamente por los medios de comunicación. Si bien es difícil rastrear una reacción propia de estos grupos más allá de las huellas plasmadas en la prensa, por la variedad temática, profundidad del análisis y contactos de la institución, es probable que haya interesado a empresarios, sindicatos, medios de comunicación, estudiantes universitarios y la Iglesia católica. Probablemente, para ellos sería un insumo, mientras que para el CEP el medio de llegada más masivo para que sus diagnósticos permearan el espacio público. Con esto, el Centro ampliaba su abanico de herramientas para los interesados en el devenir del país.

La encuesta en sí era relevante para el Centro por varios motivos. Primero, esta buscaría analizar a la sociedad chilena en relación con las transformaciones que el régimen militar había realizado, teniendo como pregunta de fondo si lo obrado por la dictadura, otros grupos de interés y el mismo CEP, había calado en la población. Algo posible si consideramos que el auge de las encuestadoras en Latinoamérica se dio bajo el impulso de los pasos del autoritarismo a la democracia, y la necesidad de entender el comportamiento ciudadano en esos procesos tan sensibles. ${ }^{31}$ Además, el diagnóstico, a su vez, podría ser un insumo de influencia en los grupos con más poder, ya sea para planificar el futuro como también para generar discursos a partir de los resultados que surgieran de las mismas encuestas, sea en talleres de análisis dirigidos al empresariado -como haría el Centro- o de parte de la prensa chilena. Tercero, es necesario reconocer una verdadera vocación académica en la realización de estos trabajos. Si bien existía un interés político detrás de las acciones de la institución, la metodología, resultados y el lenguaje utilizados eran parte de la academia de entonces. Por lo tanto, no era una academia aséptica. Por último, era importante obtener el reconocimiento de la misma comunidad académica y política para influir en ellas, entre mayor fuera el respeto a su labor, mayor posibilidad de financiamiento, relevancia y trascendencia tendría su proyecto políticointelectual.

El enfoque de las encuestas CEP tuvo algo en común con otras iniciativas de la centroizquierda, es decir, uno caracterizado de "marketing-político". ${ }^{32}$ Este análisis consistía en clasificar a la población según distintos factores, con la finalidad de establecer perfiles de los chilenos. Al dividirlos en categorías sociales, religiosas, políticas, etc., era más fácil dirigir ciertos discursos y acciones, abordando de mejor forma a un determinado grupo social con una idea específica. ${ }^{33}$ Potencialmente, tanto la oposición como oficialismo se vieron beneficiados con estos elementos.

\footnotetext{
${ }^{31}$ Huneeus, Carlos: “Las encuestas de opinión pública...", p. 18.

32 Sunkel, Guillermo: “Las encuestas de opinión pública...”, p. 17.

33 Ibid.
} 
Entre diciembre de 1986 y enero de 1987 se realizó un estudio de campo a 900 personas en Santiago, liberando los datos de la encuesta a fines del mes de mayo. Este estudio, posteriormente fue complementado con otros trabajos focalizados en grupos específicos, tales como la élite política, económica y social del país; estudiantes universitarios y trabajadores de medianas y pequeñas empresas. En busca de analizar a los grupos con más incidencia en el país. ${ }^{34}$ En todos los estudios se mostraba que los ideales de libre mercado si bien habían calado en la población, no eran una visión hegemónica, ya que estaba en disputa con el modelo de desarrollo basado en la acción estatal que había tenido Chile antes del golpe. Se mostraba más bien una transición gradual a los postulados de libre mercado.

El estudio de opinión liberado en mayo tuvo mayor repercusión. La conclusión que se obtenía de este, por lo menos en términos políticos, era la existencia de un deseo de retornar a la democracia, una despolitización de la sociedad y la creencia de que Augusto Pinochet seguiría más allá de la década. Ante la pregunta de "cuáles eran las tres mayores situaciones que usted considera que requieren mayor preocupación en la actualidad", resaltaba la cesantía (82\%), "violencia/terrorismo" (45\%); bajos sueldos (35\%), violaciones a los DDHH (34\%), delincuencia (24\%), que no haya congreso (23\%), inflación (18\%), endeudamiento (7\%) y protestas y paros (7\%). ${ }^{35}$ La encuesta y los medios mostraban una mayor preocupación de la ciudadanía por la economía, seguridad y Derechos humanos. La economía destacó por sobre otros porque era la adversidad cotidiana más urgente que debían resolver las familias chilenas, la más transversal. Esto no quiere decir que las disquisiciones políticas no hayan importado en la ciudadanía, sino que dentro de la vida diaria no se veía como lo más urgente, debido a la catastrófica experiencia económica de inicios de la década. ${ }^{36}$

\footnotetext{
${ }^{34}$ Centro de Estudios Públicos, "Estudio social y de opinión pública en la población de Santiago. Diciembre 1986enero 1987", Documento de Trabajo $\mathrm{N}^{\circ}$ 83, mayo 1987. Disponible en https://www.cepchile.cl/cep/site/artic/20160304/asocfile/20160304092801/DOCUMENTO_encDic86_1.pdf [Fecha de consulta: 6 de septiembre de 2019]; Centro de Estudios Públicos, "Estudio social y de opinión pública en el estrato alto de Santiago. Diciembre de 1986-enero de 1987", Documento de Trabajo N 84, junio de 1987; Centro de Estudios Públicos, Estudio social y de opinión pública entre estudiantes universitarios de Santiago", Documento de Trabajo $\mathrm{N}^{\circ} 88, \quad$ octubre de $1987 . \quad$ Disponible en https://www.cepchile.cl/cep/site/docs/20160304/20160304092759/DOCUMENTO_encEstudiantes.pdf [Fecha de consulta: 8 de diciembre de 2019] y Centro de Estudios Públicos, "Estudio social y de opinión pública entre trabajadores de empresas medianas y pequeñas", Documento de Trabajo $n^{\circ} 93$, noviembre de 1987. Disponible en https://www.cepchile.cl/cep/site/docs/20160304/20160304092758/DOCUMENTO_encTrabajadores.pdf [Fecha de consulta: 8 de diciembre de 2019].

35 "Encuesta: lo que piensan los chilenos", en El Mercurio, Santiago, domingo 14 de julio de 1987, p. C2.

${ }^{36}$ Chile ha tenido múltiples crisis, pero crisis del 82 se transformó en una de las más importantes de su historia. Véase Ffrench-Davis, Ricardo. 2018. Reformas económicas en Chile, 1973-2017. Neoliberalismo, crecimiento con equidad, inclusión, Santiago, Taurus, pp. 202-235; Vergara Pilar. 1984. Auge y caída del neoliberalismo, Santiago, FLACSO; Gárate, Manuel. 2014. La revolución capitalista de Chile (1973-2003), Santiago, Universidad Alberto Hurtado, pp. 283-296; Meller, Patricio. 1998. Un siglo de política económica en Chile (1890-1990), Santiago, Editorial Andrés Bello, pp. 198-210.
} 
La mayoría de la población se decía independiente, con un $46 \%$ de las preferencias. Luego, venía la indefinición política con cerca de un $23 \%$, las otras tendencias de izquierda a derecha rondaban el $4 \%$. Esto era visto por Las últimas Noticias como una realidad que planteaba "un grave problema a los partidos políticos en formación de acuerdo a la ley y que deben reunir un número determinado de firmas para su legalización". ${ }^{37}$ La Segunda, por su parte, expresaba que sería excesivo ver una politización en la sociedad al existir una identificación política tan baja en la ciudadanía. ${ }^{38}$ Ambos medios pertenecían al grupo Edwards, uno de los promotores del liberalismo económico en Chile, y resaltaban la despolitización de los chilenos y la pérdida de representatividad de las posiciones políticas tradicionales en la sociedad, especialmente la de la izquierda. ${ }^{39}$ Sin embargo, el trabajo explicaba algo similar de la derecha, también con una exigua representación. El régimen, ante su intento de despolitizar a la sociedad chilena, había logrado romper las identidades políticas de antaño que constantemente criticó. La visión de una izquierda marxista casi derrotada también era algo celebrado por los medios, ya que fomentaba la idea de que las posiciones radicales en ese sector ya no tenían cabida en la sociedad. Esto último relacionado con el infructuoso atentado a Pinochet en marzo 1986 y la fallida internación de armas en Carrizal Bajo, a mediados del mismo año.

Lo anterior adquiere más sentido ante la consulta sobre el futuro político del país. Allí la mayoría de la población deseaba la democracia en algunas de sus variantes (67\%). De este porcentaje, dos fueron las mayores tendencias sobre el tema: una levemente superior, abogaba por una democracia modificada, y la otra una democracia tal como la conocida antes de 1973 (31\%). El resto de la población (33\%) "se divide entre los que desean un sistema como el actual con modificaciones (19\%); los que no saben (10\%) y los que desearían un sistema como el actual (4\%)" ${ }^{40}$ Una amplia mayoría quería democracia, pero su contenido no estaba claro.

Sin embargo, pese a que se deseaba la democracia, la mayoría de la población creía que el general Pinochet continuaría ejerciendo su poder después de $1989 .{ }^{41}$ La sociedad chilena quería reemplazar el autoritarismo, pero existía poca confianza de que Pinochet dejara el poder. Esto era explicable por la vigencia como figura aglutinante de la política nacional -rechazo y aceptación- y también por un escepticismo de que el régimen respetase un resultado

\footnotetext{
37 “Encuestas de Opinión Pública”. Las Últimas Noticias, Santiago, 15 de junio de 1987.

38 "Preocupaciones de la población”. El Mercurio, Santiago, 16 de junio de 1987.

${ }^{39}$ Un vínculo sobre El Mercurio y su apoyo a las reformas de libre mercado se encuentra en la obra de Soto, Ángel, op. cit. y Fontaine Aldunate, Arturo. 1988. Los economistas y el general Pinochet, Santiago, Zig-Zag.

${ }^{40}$ Centro de Estudios Públicos, "Estudios Social y de opinión pública en la población de Santiago. Diciembre 1986enero 1987", Documento de trabajo CEP, $\mathrm{N}^{\circ}$ 83, mayo 1987, p. 24. Disponible en: https://www.cepchile.cl/cep/site/artic/20160304/asocfile/20160304092801/DOCUMENTO_encDic86_1.pdf [Fecha de consulta: 6 de septiembre de 2019]

${ }^{41}$ Ibid.
} 
desfavorable a sus intereses. En resumen, se aspiraba a la democracia, pero pocos confiaban en conseguirla.

Sobre el modelo económico hubo respuestas desalentadoras para sus promotores en el gobierno y la sociedad civil, cosa que era recalcada por los medios de comunicación. El Mercurio, por ejemplo, señalaba que en cuanto "a la fijación de precios, inversión extranjera, propiedad de las empresas y eficiencia de estas, la población de Santiago favorece, mayoritariamente, la política de fijación de precios. Un tercio, solamente, es partidario de la libertad en esta materia". ${ }^{42}$ Con respecto a la eficiencia de las empresas estatales y privadas, el mismo medio destacó que el 50\% "estima que las empresas estatales funcionan peor que las privadas". ${ }^{43}$ Y sobre el sistema de pensiones, mencionaban la escasa adhesión a los sistemas privados de seguridad social, como las AFP y las Isapres. ${ }^{44}$ En suma, existía dentro de la población un cuestionamiento al modelo económico y sus resultados. Probablemente fue un aviso al sector de que algo no estaba funcionando, más cuando existía la creencia que la economía era el fuerte del mismo régimen.

Es interesante que la oposición no haya hecho grandes análisis de la encuesta CEP en sus medios de comunicación, lo que hace pensar que la encuesta CEP no era tomada en cuenta por este sector en comparación con otras encuestas de instituciones como CERC o FLACSO, antes mencionadas. Algunas referencias al trabajo del Centro fueron más bien circunstanciales y para criticar el grado de asentamiento del modelo y, como se verá, solo a partir de 1988.

Sobre lo anteriormente expuesto, se deben señalar ciertos matices. Al poner en perspectiva los datos, el hecho de que un país con una tradición estatista tan asentada en su historia estuviera aceptando -gradualmente- algunas ideas liberales, era una victoria. Pero una que igualmente generaba alarma, más cuando este proceso de "transición ideológica" se había realizado hacía más de diez años, quedando según el itinerario constitucional poco tiempo para el plebiscito que decidiría el futuro de Chile.

En síntesis, el resultado expresado en aquella encuesta cuestionaba el optimismo de la derecha como también la oposición revolucionaria a Pinochet. Por un lado, algo que también recogió Arturo Fontaine Talavera, las encuestas tuvieron un efecto "devastador para las posiciones radicalizadas de la izquierda: la población no está polarizada, valora el orden, quiere llegar a la democracia a través de las reformas pacíficas y moderadas" ${ }^{45}$ Por otro, el modelo

\footnotetext{
42 "Encuesta: lo que piensan los santiaguinos". El Mercurio, Santiago, domingo 14 de junio de 1987, p. C2. 43 Ibid.

44 Ibid.

${ }^{45}$ Fontaine Talavera, Arturo. 1992. "Sobre el pecado original de la transformación capitalista”, en Barry B. Levine, EI desafío neoliberal. El fin del tercermundismo en América Latina, Bogotá, Norma, p. 121. Esto también fue comentado por Carlos Huneeus, quien explicó que las encuestas como las del CERC ayudaron a la Concertación a tomar la vía institucional. Véase Huneeus, Carlos: "Las encuestas de opinión pública...", p. 19.
} 
que con tanto ahínco se había promovido en el país no cuajaba del todo, no había logrado "legitimarse políticamente en la población" ${ }^{46}$ El hecho de que el CEP fuese el que proveyera los resultados potencialmente pudo hacer más confiable los resultados para la derecha. Sin embargo, salvo la publicación de los resultados, no se vislumbra ninguna repercusión o reflexión de los medios sobre estos datos. Es decir, los diagnósticos de la institución fueron divulgados, pero al parecer no se valoró en gran medida los datos dentro de la opinión pública. En este sentido, cabe preguntarse si los diagnósticos del Centro se tomaron en cuenta camino al plebiscito de 1988 .

\section{El CEP y el plebiscito de 1988: cuestionamientos y legitimidad}

Las encuestas realizadas en 1988 tuvieron una mayor relevancia que las de años anteriores. En aquella ocasión el objeto de análisis fue el clima de opinión frente al plebiscito que decidiría la continuidad o no del general Augusto Pinochet como gobernante hasta 1997. El tema en sí era complejo para el CEP, ya que existía la posibilidad de que las encuestas tuvieran un carácter performativo, es decir, que al tiempo que eran presentadas a la sociedad, se constituían como un elemento de cambio de esta. ${ }^{47}$ Lo anterior, ante un contexto tan polarizado implicaba que sus datos podían favorecer a uno u otro bando, no solo a través de su conocimiento técnico, sino que también a través del uso propagandístico de este en el espacio público. Por aquello, la institución evitó un compromiso activo en el plebiscito. Ya fuese en sus discusiones internas o apariciones públicas, constantemente intentaba reflejar un trabajo ecuánime entre los partidos políticos, aunque resaltando los puntos que les interesaban. De esta forma, fuese cual fuese el resultado, podría conservar el prestigio ganado con anterioridad y el respeto que generaba en parte de la oposición. Era una forma de supervivencia en un contexto polarizado. Esto en un contraste marcado con otras instituciones cercanas al sector, que ya sea por indicación de la Junta o propio convencimiento -es algo difícil de saber-, utilizaron los sondeos de opinión en un sentido más propagandístico que científico, al entregar resultados que beneficiaron a la dictadura hasta el final del mismo plebiscito, sin considerar información contraria a esto, aunque viniese de su propio sector.

\footnotetext{
${ }^{46}$ Arturo Fontaine Talavera, "Sobre el pecado original de la transformación capitalista", 121.

${ }^{47}$ Aunque esto todavía era algo conflictivo, tal como se ve en Kavanagh, Dennis. Verano 1994. "Las encuestas de opinión pública”, Estudios Públicos, №53, pp. 145-170 y Gálvez Muñoz, Luis A. 2011. "Las encuestas electorales y el debate sobre su influencia en las elecciones", en Revista Mexicana de Opinión Pública, México D. F., 11, pp. 25-43; Toff, Benjamin. 2018. "Exploring the effects of polls on public opinión: How and when media reports of policy preferences can become self-fulfilling prophesies", Research and Politics, pp. 1-9.
} 


\section{Las críticas a la encuesta CEP}

Las encuestas del año 1988 fueron financiadas por dos instituciones. Los estudios del gran Santiago corrieron por cuenta del National Endowment for Democracy, mientras que los estudios de mayor alcance a nivel nacional, con una representatividad de cerca del $85 \%$ de la población, se realizaron con aportes del National Republican Institute for International Affairs. Los recursos de este último ascendían a \$US 221.000, y estaba destinado a financiar a la empresa ADMIMARK, que llevaría a cabo el estudio de campo. ${ }^{48}$ Sin embargo, pese a que la encuesta tendría una representatividad del $85 \%$ de la población nacional, Eliodoro Matte, en ese entonces presidente de la Fundación del CEP, propuso ampliarla para tener la mayor certeza posible. Fue así como Arturo Fontaine Talavera realizó nuevas gestiones para obtener un financiamiento que asegurase una representatividad cercana al 100\%, al incluir a las comunidades rurales de menos de 20.000 habitantes. ${ }^{49}$ La búsqueda de exactitud era de interés compartido por los miembros del comité ejecutivo de la institución, y respondía al escenario de incertidumbre sobre el devenir del país como también a la necesidad de realizar el mejor trabajo posible, puesto que también se jugaba el prestigio institucional ante todo el espectro político. Lo obrado a través de los años podría ser juzgado en estos sondeos de la opinión.

ADIMARK fue una empresa fundada por Roberto Méndez y Francisco Matte en el segundo lustro de la década de 1970. Según Méndez, en ese entonces estaba prohibido hacer mediciones de tipo político, por lo que ingresaron en primera instancia al mundo comercial, aunque aun así "los cuestionarios eran revisados previamente por funcionarios de Gobierno". Solo pudo concretar análisis políticos en la década de 1980, como consecuencia del proceso de apertura. ${ }^{50}$ La primera de este tipo para ADIMARK la realizó con la revista Qué Pasa, pero este medio "finalmente no la publicó". Pese a lo anterior, Méndez distribuyó la encuesta en el mundo empresarial e incluso el general Pinochet le pidió que le presentara su trabajo. ${ }^{51}$ En 1987 Arturo Fontaine, interesado en las encuestas, lo llamó para asociarse a la hora de realizar estos trabajos camino al plebiscito. ${ }^{52}$

El celo por mostrar que la institución era autónoma de otros partidos políticos, grupos de interés o del gobierno hizo que se contemplara la posibilidad de dejar de recibir fondos de

\footnotetext{
${ }^{48}$ Sesión Especial del Consejo Directivo n² 2/1988, Santiago 7 de abril de 1988, p. 2.

${ }^{49}$ Sesión Especial de Consejo Directivo n 3/1988, Santiago 14 de junio de 1988, pp. 2-3.

${ }^{50}$ Sobre apertura véase Huneeus, Carlos. 2016. El Régimen de Pinochet, Santiago, Taurus, pp. 485-487. También Arancibia Clavel, Patricia, Arancibia Floody, Claudia y de la Maza Cave, Isabel. 2002. Jarpa. Confesiones políticas, Santiago, La Tercera-Mondadori; Aylwin, Patricio. 1998. El Reencuentro de los demócratas, Santiago, Ediciones B, pp. 186-224; Huneeus, Carlos. 1985. "La apertura política y sus implicancias", en Revista de Ciencia Política, Santiago, vol. VII, 1, p. 29.

${ }^{51}$ Entrevista realizada por el autor a Roberto Méndez el 27 de junio de 2018

52 Ibid.
} 
instituciones extranjeras como la NED, de vital importancia en la realización de los sondeos de opinión. En diciembre de 1987, mientras se discutía la Ley de Presupuestos en Estados Unidos, el senador Tom Harkin, miembro del Partido Demócrata, impulsó una enmienda que comprometía ayuda al proceso de transición a la democracia chilena mediante la disposición de un fondo de un millón de dólares. Esto fue aprobado y los fondos fueron distribuidos por la NED a organizaciones proelecciones libres dentro del país. ${ }^{53} \mathrm{El}$ revuelo generado en Chile fue importante, pues el gobierno alegó intervencionismo extranjero. Un comunicado del Ministerio de Relaciones Exteriores reproducido por La Época, repudiaba “una vez más, esta inaceptable intromisión en asuntos internos de Chile y de incumbencia soberana de los ciudadanos chilenos, quienes son los únicos a quienes legítimamente corresponde adoptar sus resoluciones, sin injerencia ni presiones extranjeras de ninguna especie". ${ }^{54}$ El Mercurio, que bien reflejaba el sentir nacionalista del régimen, ponía el acento en que el país norteamericano financiaba a la oposición, con títulos como: "Un millón de dólares para la oposición chilena" o "EE. UU. Entregó US\$2,6 millones a la oposición chilena" ${ }^{\prime 55}$. Esto, en parte, siguiendo la estrategia del régimen de apelar al nacionalismo y mostrar a la comunidad internacional hostil a su gobierno, y por tanto de Chile. ${ }^{56}$

Que el Centro recibiera fondos del NED pudo ser mal visto incluso por los propios miembros del Directorio, quienes en caso alguno querían aparecer vinculados a una maniobra que el régimen militar consideraba intervencionista. El cuestionamiento tenía importancia, puesto que la Junta y sus aliados civiles cuestionaban que diferentes instituciones de Estados Unidos, tales como la NED o la Fundación Ford, hubieran aportado cerca de seis millones de dólares sin contar el millón contribuido por el NED- de cerca de un total de 20 millones de aquella divisa que diferentes organizaciones de la oposición -como think tanks o la misma campaña del NO-

\footnotetext{
53 “Un millón de dólares para la oposición chilena”. El Mercurio, Santiago, 23 de diciembre de 1987, pp. A1 y A10.

54 "Sergio Molina negó que el CEL reciba fondos directos de fundación de EE. UU.". La Época, Santiago, 24 de diciembre de 1988, p. 11. La polémica siguió en los meses venideros, ver el reportaje "Absoluto rechazo al envío de dinero a la oposición chilena". La Tercera, Santiago, 16 de marzo de 1988 o también el artículo "EE. UU. entregó US\$ 2,6 millones a oposición chilena". El Mercurio, Santiago, 4 de junio de 1988.

55 Ibid; “EE. UU. Entregó US\$ 2,6 millones a Oposición Chilena”, El Mercurio, Santiago, 4 de junio de 1988.

${ }^{56}$ Es necesario recordar el discurso anti intervención norteamericana que la dictadura llevó a cabo en ese entonces. Algo acentuado por las críticas del país norteamericano a la violación a los Derechos Humanos en Chile y la condena al asesinato de Orlando Letelier en Washington, realizado por agentes de la DINA. Para una aproximación a la política exterior de la dictadura. Sobe las relaciones internacionales del período véase Fermandois, Joaquín. 2005. Mundo y fin de mundo. Chile en la política mundial 1900-2004, Santiago, Ediciones UC, especialmente capítulos XIV y XV, donde aborda los años del régimen; Fermandois, Joaquín. 1991. "De una inserción internacional a otra", en Estudios Internacionales, № 96, pp. 433-455; Muñoz, Heraldo. 1986. La política exterior del gobierno militar chileno, Santiago, Ediciones del Ornitorrinco; y Portales, Carlos. 1993. "Los factores externos y el régimen autoritario", en Paul W. Drake e Iván Jaksic (eds.), El difícil camino hacia la democracia 1982-1990, Santiago, FLACSO, pp. 455-498.
} 
recibieron entonces. ${ }^{57}$ Esto tomó más fuerza cerca de la fecha de plebiscito cuando medios como La Segunda explicaban que: "casi la totalidad de los organismos favorecidos son manejados por opositores", salvo el CEP. ${ }^{58}$ Un hecho que pudo mostrar al CEP alineado con una oposición internacional a Pinochet.

La trascendencia de lo anterior radica en la creciente oposición de Estados Unidos al régimen de Pinochet. Al inicio de la administración de Ronald Reagan la oposición directa a Pinochet disminuyó, pero con el auge de la represión política y el decreto de Estado de Sitio en 1984 la percepción en Washington se fue haciendo más crítica, ya que lo veían como parte del problema del país. Según explica Pablo Rubio, EE. UU. buscó apoyar a una oposición y derecha chilena no pinochetista, buscando de este modo proyectar el modelo económico, consolidar la exclusión del comunismo y contribuir a la estabilidad democrática de Chile. Un programa que fue compartido desde el Centro. ${ }^{59}$

Por lo mismo, y posiblemente en vista del apoyo de algunos donantes y de los fundadores del CEP que apoyaban a Pinochet, es que Arturo Fontaine Talavera decidió emitir un comunicado para explicar la relación del Centro con el NED. Allí, a través de seis apartados, explicaba que el vínculo existía desde 1986 y que era parte de un trabajo en colaboración con la Universidad de Carolina del Sur. Añadieron que su objetivo era realizar sondeos de opinión y publicar trabajos analizando los mismos resultados. ${ }^{60}$ Como medida para evitar la polémica suscitada con la enmienda Harking, en vista que su aporte era considerado una "contribución de tipo político", según las actas del Centro, se decidió "no recibir aportes del NED provenientes de dicha enmienda", aunque intentó continuar la relación con la institución estadounidense siempre y cuando su financiamiento no proviniera de aquella. ${ }^{61}$ El vínculo con el NED siguió su curso al expresarse, por medio de una carta, que los aportes que el Centro recibiría no provendrían de la mencionada enmienda. ${ }^{62} \mathrm{Si}$ bien el fondo de un millón de dólares era considerado como un acto político por los cercanos al CEP, nos parece interesante que no hayan considerado como una acción política lo obrado por el mismo NED a lo largo del tiempo. El fondo tendría un origen político, más no la propia institución que ya había financiado al Centro

\footnotetext{
${ }^{57}$ Molina Armas, Pilar "Platas negras, blancas... y políticas”. Reportajes El Mercurio, Santiago, 24 de enero de 1988, pp. D1, D4-D5.

58 "Congreso de EE.UU. adjudicó platas a 8 organismos chilenos". La Segunda, Santiago, 24 de marzo de 1988.

59 Rubio Apiolaza, Pablo. 2019. "Los Estados Unidos y la transición a la democracia en Chile: lecturas e influencias entre 1985 y 1988", Documentos de Trabajo IELAT, n 120.

60 “Aclaran relación CEP-NED”. La Época, Santiago, 24 de diciembre de 1987, p. 11.

${ }^{61}$ Sesión Especial de Consejo Directivo n 1/1988, en Santiago 13 de enero de 1988, p. 2.

62 Sesión especial de Consejo Directivo n²/1988, en Santiago 7 de abril de 1988, p. 2.
} 
en otras ocasiones. ${ }^{63}$ Una distinción práctica de los miembros del Directorio, útil para salir del paso de la polémica como también para continuar recibiendo sus aportes.

En julio de 1988 se publicó una encuesta basada en el estudio del Gran Santiago, anticipando así lo que sería el trabajo a nivel nacional. En ella se expresaron varios puntos sobre la coyuntura plebiscitaria, entre los que se destacaron tres por parte de los medios de comunicación: el empate entre el Sí (36\%) y el NO (36\%); la importancia de los indecisos (28\%); una importante crítica a la situación económica del país, además de una tendencia a la moderación del país. ${ }^{64}$ Estas conclusiones no eran alentadoras para la derecha, y mucho menos para el régimen, especialmente en lo referente al modelo económico, caballo de batalla de la propaganda del régimen, aunque mantenía como una posibilidad cierta su victoria del 5 de octubre, algo que también aparecía en otros sondeos (véase cuadro $n^{\circ} 1$ ).

Cuadro $\mathrm{n}^{\circ} 1$ : Resultados encuestas abril-junio 1988

\begin{tabular}{|c|c|c|c|c|c|c|}
\hline & $\begin{array}{c}\text { Gallup (abril } \\
\text { 1988) }\end{array}$ & $\begin{array}{c}\text { U de Chile } \\
\text { (abril 1988) }\end{array}$ & $\begin{array}{c}\text { Skopus } \\
\text { (abril 1988) }\end{array}$ & $\begin{array}{c}\text { Flacso (abril } \\
\text { 1988) }\end{array}$ & $\begin{array}{c}\text { Gallup } \\
\text { (junio 1988) }\end{array}$ & $\begin{array}{c}\text { U de Chile } \\
\text { (julio 1988) }\end{array}$ \\
\hline SI & 36 & 36,2 & 24,5 & 25,8 & 42,1 & 38 \\
\hline NO & 29 & 29,1 & 19,1 & 27,6 & 33,4 & 32 \\
\hline Indeciso & 35 & 34,7 & 44,5 & 33,3 & 24,5 & 30 \\
\hline
\end{tabular}

Fuente: elaboración propia a partir de datos extraídos de Marti, Gerardo y Valenzuela, Pablo. Noviembre diciembre 1988. “¿Cómo abordar las próximas elecciones presidenciales?”, Economía y Sociedad, N 72, p. 9.

En el CEP explicaban que una de las motivaciones para realizar este tipo de encuestas era "llegar a conocer las predisposiciones y tendencias preferidas que están afectando a los votantes", para -a partir de ellas- conocer las predilecciones que se expresarían electoralmente. ${ }^{65}$ Destacaban, según lo recogido por La Segunda, que de este modo sería un aporte a las campañas políticas. Así, citando posiblemente a un miembro del consejo ejecutivo del CEP, "dadas las percepciones, se presume que las campañas políticas adquirirían un tono emotivo y personal, en un esfuerzo por interpretar la inquietud de los grupos blandos y

\footnotetext{
63 Juan Jesús Morales Martín aborda la relación de organismos internacionales en el caso de centros de estudios chilenos, teniendo como foco la relación entre la Fundación Ford y CIEPLAN. Allí se muestra que las agencias internaciones tienen una agenda política que las instituciones deben seguir para recibir fondos. Algo que el autor entiende como "dominación filantrópica". Véase Morales Martín, Juan Jesús. 2018. "Dominación filantrópica y gobernabilidad democrática: el caso de la Fundación Ford y CIEPLAN en Chile (1976-1990)", en Historia, Santiago, vol. 51, N¹, pp. 141-153.

64 "Un Empate entre el 'Si' y el 'No' indica encuesta CEP”. El Mercurio, Santiago, 25 de julio de 1988; "El 55,2 por ciento de los chilenos considera de mala a pésima la situación económica imperante en el país". La Época, Santiago, 17 de julio de 1988, 27; "Indecisos decidirán plebiscito". La Tercera, Santiago, 6 de julio de 1988; "Encuesta sobre indecisos en el Gran Santiago". La Segunda, Santiago, 5 de julio de 1988, pp. 9, 31 y última.

${ }^{65}$ Santa Cruz, Lucía, “Quien sería mejor candidato, según las encuestas". La Segunda, Santiago, 25 de julio de 1985.
} 
atraerlos". ${ }^{66}$ Agregaba que con una "campaña agresiva, de antimarxismo duro, condenatorio y gastado puede obtener resultados contraproducentes" ${ }^{67}$ De este modo, el Centro mostraba un panorama perjudicial para campañas basadas en la confrontación y el miedo. El que no apelara a emociones positivas, tendría problemas para atraer a los grupos con preferencias políticas menos marcadas dentro de la población. Algo que la campaña del NO coincidió al realizar un diagnóstico similar, pero que el sí desechó al inclinarse por una campaña basada en el miedo, algo con importantes consecuencias para sus aspiraciones. Una vez que se pusieron ambas campañas en marcha, parecía que el CEP no tenía llegada en el equipo comunicacional del Sí, pero estaba en sintonía en el análisis con el equipo del NO. ${ }^{68}$

Sin embargo, al poco tiempo que se publicaron los resultados del estudio del CEP, otra empresa -cercana al régimen- entregaba sus propios datos: Skopus. Esta encuestadora lejos de mostrar información similar a la del CEP, daba una amplia victoria a la opción Sí, con cerca de un 59\% frente a un 40\% de la opción NO. ${ }^{69}$ Explicaban los representantes de Skopus que el sondeo era "probabilístico en todas sus etapas, cubriendo en un mismo período a sectores urbanos y rurales, incluso los más alejados".$^{70}$ Llegaron a la conclusión de que por cada votante del NO, había 1,5 votantes del Sí. De este modo, ante la interrogante de por qué la encuesta CEP era tan distinta en sus resultados a la de Skopus, un medio como Ercilla señaló, luego de varias consultas, que entre otras cosas la metodología del CEP era "deficiente". ${ }^{71}$ Dentro de la misma derecha el CEP era criticado por los resultados de su trabajo, probablemente porque se alejaban del anhelo oficial y de las aspiraciones de buena parte de la derecha respecto de los resultados del plebiscito. Por lo menos esto es lo que creía Arturo Fontaine Talavera, quien veía en los cuestionamientos a un gobierno disconforme que atacaba mediante empresas contratadas. ${ }^{72}$ Paradojalmente, también reconocía Fontaine Talavera, que aquello fue importante para el CEP porque les otorgó notoriedad en la escena nacional. ${ }^{73}$ Esto se corrobora con el aumento de menciones en sobre el CEP en la época, como se apreció en el gráfico $n^{\circ} 1$.

De este se originó una polémica, ya que el cuestionamiento también lo hizo directamente Skopus. En una reunión de esta empresa y la Universidad de Chile con el CEP, los primeros criticaron la metodología de las encuestas realizadas por el Centro, en algo que posteriormente

\footnotetext{
${ }^{66}$ Ibid.

67 Ibid.

${ }^{68}$ Un estudio sobre la elección de 1988 se encuentra en Joaquín Fermandois y Ángel Soto, "El plebiscito de 1988. Candidato único y competencia", en San Francisco y Soto (eds.), op. cit., pp. 371-399.

69 “Decisión ad portas". Ercilla, № 2765, Santiago, semana del 27 de julio al 2 de agosto de 1988, p. 6.

70 lbid. p. 7.

71 lbid., p. 8.

72 Entrevista realizada por el autor a Arturo Fontaine Talavera el 30 de enero de 2017.

73 Ibid.
} 
se consideró como un ataque orquestado por el régimen militar. ${ }^{74}$ Sobre esto se pensaba entonces que se quería "destruir la encuesta CEP, ya que en el gobierno no gustaba tener noticias de unos resultados no tan cercanos al régimen dentro de su mismo sector político". ${ }^{75}$ Según lo reporteado por La Segunda, "Davinovic, experto estadístico que trabaja en Skopus, argumentó que los resultados del CEP no eran válidos, ya que la muestra utilizada tiene errores, entre ellos el hecho de que las personas encuestadas no tienen cada una la misma probabilidad de ser seleccionadas". ${ }^{76}$ La respuesta del director del CEP no se hizo esperar, y explicó que la firma Brockbanck Inc. de Estados Unidos y la chilena ADIMARK eran líderes en su ámbito, en el extranjero y en Chile, respectivamente. Además, mencionaba que la metodología usada era muy similar a la que dio por ganador a Ronald Reagan en 1980, un resultado que finalmente se hizo realidad. ${ }^{77}$

Roberto Méndez, director de ADIMARK también se refirió a la calidad de la muestra. Él explicó la metodología, al tiempo que se refería a la cantidad y calidad de los trabajos realizados por él, el CEP y sus asesores. Concluía que: "afirmar que toda esta forma de trabajo, en base a la cual se están tomando muchas decisiones importantes en el mundo, 'carece de toda validez', es por decir lo menos, aventurado". ${ }^{78}$ Algo similar también expresaba Vincent J. Brelio, el profesional norteamericano encargado de dirigir el trabajo del CEP, quien añadía que por la metodología y la cantidad de encuestados -mayor en Chile que en algunos exitosos estudios en el extranjero-, el trabajo del CEP reflejaba "fielmente la opinión de los chilenos sobre el plebiscito". 79

Lo más interesante de esto es que el Centro integró las críticas realizadas por Skopus, para ver si el resultado variaba considerablemente, no obstante aquello no se visualizó, ya que el resultado todavía daba una ventaja a la opción NO. ${ }^{80}$ La discusión sobre la validez de las encuestas no era menor, más cuando estas tomaban protagonismo en la escena pública. A las críticas realizadas a algunas encuestadoras -como Gallup- de tener una "función de apoyo

\footnotetext{
74 “¿Qué pasó?”. Qué Pasa, N 914, Santiago, semana del 13 al 19 de octubre de 1988. Allí se explicó que “En junio (sic), el Gobierno replicó a sus resultados con enviados de Skopus, que criticaron su metodología". La discusión se desarrolló durante el mes de julio, no de junio como cita el medio.

75 “El última apronte”. Qué Pasa, № 904, Santiago, semana del 4 al 10 de agosto de 1988, p. 6.

76 "Reunión técnica y discusión estadística entre equipo de encuestas de CEP y Skopus”. La Segunda, Santiago, 25 de julio de 1988.

77 lbid; también se reafirmó lo anterior en una carta al director de Gabriel Davinovic Moinar, "Discusión ténica entre CEP y Skopus". La Segunda, 28 de julio de 1988.

${ }^{78}$ Carta al director de Roberto Méndez, "Discusión técnica sobre encuestas (CEP y Skopus)". La Segunda, Santiago, 27 de julio de 1988.

${ }^{79}$ Carta al director de Vincent J. Brelio, “Métodos de encuestas CEP y Skopus". La Segunda, Santiago, 12 de agosto de 1988.

80 “El última apronte”. Qué Pasa, № 904, semana del 4 al 10 de agosto de 1988, p. 6.
} 
psicológico a la campaña de Pinochet", se sumaban discusiones metodológicas entre una y otra en afán de deslegitimar el trabajo de los rivales. ${ }^{81}$ Existían muchos estudios que a la vez que aportaban conclusiones para las campañas políticas en una coyuntura sensible, también podían influir en la población. De este modo, más que interesar la defensa del Centro o lo certero de sus datos, llama la atención que haya existido una crítica entre encuestadoras involucrando incluso a la Universidad de Chile, en ese entonces intervenida por el gobierno, en aras de deslegitimar el trabajo de una encuesta surgida desde el campo de la derecha que mostraba datos contrarios a los esperados por el oficialismo.

\section{La encuesta y el plebiscito: consolidación}

El 3 de octubre de 1988, el CEP iba a publicar la última encuesta que había realizado a nivel nacional. Los resultados serían importantes ya que podrían dar indicios certeros de cuál sería la opción ganadora, a solo dos días de las elecciones. Sin embargo, esta no se hizo pública, probablemente debido a los malos números que esta traía para el sector y que significaba la derrota del Sí. Que una encuesta vinculada a la derecha publicara la derrota de su propio sector no era buen augurio, pudiendo además influir negativamente en el electorado oficialista. A causa de ello, el CEP dejó en custodia notarial los resultados, sin divulgar públicamente sus conclusiones. Pero ello no significó que no fuesen contundentes.

La derecha política había tenido acceso a los resultados en forma privada. ${ }^{82}$ Incluso desde el Comando del NO -opción opositora- sabían que la campaña del Sí contaba con las encuestas adversas a su misión, pero no confiaban en lo que veían. Pese a tener este tipo de instrumentos, no creían la información que recolectaba, al menos eso pensaba Genaro Arriagada, uno de los líderes de la Campaña del NO. ${ }^{83}$

Divulgados los datos en esta reunión reservada, las caras de decepción abundaron, e incluso aparecieron personas que no creían en tales resultados. El ministro del interior, Sergio Fernández, cotejaba los datos del CEP con sus informaciones que daban a Pinochet como ganador, y al darse cuenta de la posible derrota, expresó que estaban siendo engañados por los intendentes a los que les pedían informaciones. ${ }^{84}$ Según Óscar Godoy, probablemente los militares al ser consultados por el gobierno central si se había logrado el porcentaje deseado por la institución, respondían afirmativamente porque confundían el "deseo" de que así fuese en sus círculos cercanos con un informe real de los intereses de la población. ${ }^{85}$

\footnotetext{
${ }^{81}$ Vicente Parrini, "El desacuerdo de los adivinos". Apsi, № 263, Santiago, semana del 1 al 7 de agosto de 1988, p. 7.

82 "Encuesta no divulgada del CEP da 52\% al NO y 32\% al Si". La Época, Santiago, 5 de octubre de 1988.

${ }^{83}$ Esto se encuentra en Arriagada, Genero. 1998. Por la razón o la fuerza. Chile bajo Pinochet. Santiago, Editorial Sudamericana, p. 256.

${ }^{84}$ Entrevista realizada por el autor a Óscar Godoy el 22 de mayo de 2018.

$85 \mathrm{Ibid}$.
} 
El país se enteró el mismo día del plebiscito a través de una filtración de los datos de la encuesta -realizada por Arturo Fontaine Talavera vía embajador de Estados Unidos- por parte de la corresponsal del New York Times en Chile para el plebiscito, Shirley Christian, quien publicó un resultado favorable para el NO de un $52 \%$, mientras que el Sí obtenía un $32 \% .{ }^{86}$ Solo si todos los indecisos se inclinaban por el sí, esta podría haber ganado, por lo que la derrota del oficialismo se avizoraba inminente. Algo que finalmente sucedió con un resultado demorado y con el intento de Pinochet por desconocerlos. ${ }^{87}$ Los resultados darían finalmente 55,99 para el NO y un $43,01 \%$ para la opción sí. ${ }^{88}$

Cuadro $\mathrm{n}^{\circ} 2$ : predicciones y resultados del plebiscito de 1988

\begin{tabular}{|c|c|c|c|c|c|c|c|c|}
\hline & 岂 & 沜 & 岂 & 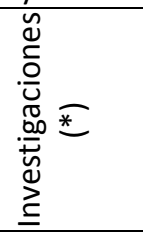 & 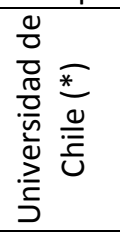 & $\begin{array}{l}\frac{n}{0} \\
\frac{0}{0} \\
\frac{0}{n}\end{array}$ & $\frac{\stackrel{2}{3}}{\frac{\sqrt{0}}{0}}$ & 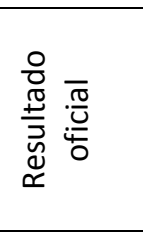 \\
\hline SI & $32 \%$ & $20,8 \%$ & $\begin{array}{c}35,7 \\
\%\end{array}$ & $\begin{array}{c}53,95 \% \\
(52,68 \%)\end{array}$ & $\begin{array}{c}52 \% \\
(54 \%)\end{array}$ & $55,3 \%$ & $47 \%$ & $43,04 \%$ \\
\hline NO & $52 \%$ & $54,5 \%$ & $\begin{array}{c}43,8 \\
\% \\
\end{array}$ & $\begin{array}{c}46,75 \% \\
(47,32 \%)\end{array}$ & $\begin{array}{c}44 \% \\
(46 \%)\end{array}$ & $46,1 \%$ & $42 \%$ & $54,68 \%$ \\
\hline Indecisos & $16 \%$ & $24,8 \%$ & $\begin{array}{c}20,5 \\
\% \\
\end{array}$ & - & $4 \%$ & - & - &.- \\
\hline Nulos/blancos & & - & - & - & - & - & $11 \%$ & $2,28 \%$ \\
\hline
\end{tabular}

Fuente: Gráfica extraída de “Quién anduvo más cerca”. Qué Pasa, N 914, Santiago, semana del 13 al 19 de octubre de 1988, p. 15.

Conocidos los resultados llegó el tiempo de la reflexión. En lo concerniente a las encuestas hubo una crítica a la capacidad predictiva de estas, debido a que muchas de las que daban la victoria al Sí por un amplio margen -vinculadas al gobierno en su mayoría- habían errado espectacularmente. Fue amplia la crítica en la prensa por la equivocación del resultado final del plebiscito, aunque previamente no se hizo un cuestionamiento en los medios, incluso publicando en primera plana sondeos que indicaban sendas victorias para el Sí el mismo día de este. Encuestas como Skopus daban como ganador al sí con un 55,3\% frente a un $44,7 \%$ que

\footnotetext{
${ }^{86}$ Christian, Shirley, "Pinochet Foes, Bolstered by Polls, Hope to Oust Him in Vote Today". The New York Times, Nueva York, 5 de octubre de 1988. También, en entrevista realizada por el autor a Arturo Fontaine Talavera el 14 de mayo de 2018.

${ }^{87}$ Sobre Pinochet día de plebiscito, véase Cavallo, Ascanio. 2008 [1998]. "Capítulo 53", La historia oculta del régimen militar, Chile 1973-1978, Santiago, Uqbar, edición EPUB.

${ }^{88}$ Sobre el intento de desconocimiento de las elecciones véase la entrevista al ex General del Aire Fernando Matthei, en el programa Mentiras Verdaderas, La Red, martes 2 de agosto de 2016: https://www.youtube.com/watch?v=5ucZcbQj12o\&t=346s
} 
tendría el NO. ${ }^{89}$ Algo similar sucedió con la Policía de Investigaciones, en ese entonces interesada en producir sondeos de opinión, la U. de Chile -ambas dependientes del Estado- y la empresa privada Gallup. ${ }^{90}$ Si ya se desconfiaba de algunos resultados con anterioridad, con el plebiscito la cuestión de fondo que surgió fue la manipulación de los datos en beneficio del régimen, algo que, si bien era desmentido, se apreciaba en la constante equivocación de las encuestas encargadas por el gobierno hasta el último momento. Las encuestas habían sido usadas como un instrumento de propaganda.

La responsabilidad por el fracaso del sí era achacada desde el régimen hasta las empresas encuestadoras. Uno culpaba al otro, y ninguno asumió la responsabilidad por lo poco fiable de los datos entregados. ${ }^{91}$ Sin embargo, por lo constante del error y lo abultado de las diferencias, la responsabilidad era compartida. La acusación central era que el régimen había utilizado las encuestas para proyectar su victoria y convencer a la población de su casi seguro triunfo. Había sido un instrumento propagandístico para la campaña del sí que, en aras de beneficiar a esta posición, paradójicamente, no hizo más que engañar al propio gobierno y a sus adherentes. No consideraron los sondeos como un instrumento para mejorar sus políticas y adaptarse a los deseos ciudadanos, perjudicándolos en la carrera electoral. Fue una ilusión, un autoengaño, que en nada benefició al régimen.

En este contexto, Roberto Méndez, director de ADIMARK se sumó a las críticas por el mal uso de estos sondeos en política. Allí explicaba que había un grupo de encuestas pertenecientes a los centros académicos independientes que se acercaban al resultado, y otras que derechamente erraron. Alegaba que los errados pertenecían a "diversos estudios encargados por el Gobierno, y cuyos resultados solo fueron conocidos a través de los medios de comunicación". 92 Y para explicar el por qué de la equivocación, sugería dos explicaciones: “o quienes realizaron estos estudios son personas de una gran incompetencia profesional o esos resultados fueron definitivamente manipulados y distorsionados". 93 Aquello daba muestra de una irresponsabilidad que rayaba en lo delictual. ${ }^{94}$ Méndez sostenía, con respecto a la segunda opción, que esto era grave y que era necesario investigarlo. Para él, la "distorsión de la verdad

\footnotetext{
${ }^{89}$ Armas Molina, Pilar, "El fracaso de las encuestas". El Mercurio, Santiago, 9 de octubre de 1988, p. D7. 90 Ibid.

91 “Experiencia para tener en cuenta”. Publimark, Santiago, 10 de noviembre de 1988, pp. 18-21; “¿Manipulables o manipuladas?". Qué Pasa, № 916, Santiago, semana del 27 al 2 de noviembre de 1988, pp. 35-38.

92 Roberto Menéndez, “Encuestas de Opinión Pública y Plebiscito”. El Mercurio, Santiago, 22 de octubre de 1988. 93 Ibid.

94 Roberto Méndez en el seminario “¿Por qué ganó el NO?”. Disponible en https://www.cepchile.cl/cep/site/artic/20180913/asocfile/20180913130013/aua 19881010 porque gano el n o roberto mendez enrique barros oscar godoy arturo fontaine.mp3, minuto 44:00 a 46:00. [Fecha de consulta: 6 de septiembre de 2019]
} 
en cualquier forma no puede ser aceptada éticamente como arma de lucha política; los resultados de encuestas incluidos". ${ }^{95}$ El problema de fondo era la manipulación de la información para influir en las decisiones electorales de la ciudadanía, más cuando esta manipulación podía significar el fin del régimen autoritario y una aceleración en el proceso de redemocratización. Era consciente del efecto que podían tener encuestas mal intencionadas en las decisiones de la ciudadanía, y en la injerencia directa de estos instrumentos en el futuro de los países. Era una referencia evidente a la disputa con Skopus desarrollada algunos meses antes.

Posteriormente Eduardo Hamuy fue más explícito. En ese entonces era miembro del Consejo de Elecciones Libres al tiempo que colaboraba con CERC. Afirmaba que lo hecho por algunas empresas de encuestas era olvidar todo lo científico de ellas. Explicaba en una entrevista que: "o se quiere conocer la opinión pública o es un instrumento de propaganda y esto es inmoral". ${ }^{96}$ Esto último sería lo que sucedió con varias encuestas previas al plebiscito de 1988, por lo que agregaba que por esto "hay encuestas que deberían quedar fuera del mercado", porque había "fallas morales graves". ${ }^{97}$ La sospecha de que algunas eran un instrumento de propaganda era común, algo que en el futuro influiría a la hora de mensurar esta actitud en la elección posterior de 1989.

Pero al tiempo que se criticaba el mal uso de los sondeos de opinión, también se defendía su utilización en el futuro. El estudio de opinión, al realizarse de una manera profesional, "era el medio más objetivo de mantenerse en contacto con la realidad". ${ }^{98}$ Algo que de por sí podía beneficiar a los grupos políticos, como también sugería al mencionar que "quedó claro quiénes recogieron estas señales [las encuestas] y quiénes no" a la hora de realizar la campaña en el plebiscito. En suma, pese a lo desprestigiado de algunos sondeos, el CEP -al igual que otros centros de investigación de oposición-abogó por el uso de las encuestas en la política, ya que estas serían un trabajo científico de la realidad que podría entregar a los políticos las necesidades de las personas. Esto, a su vez, tenía otro problema mayor: el que la opinión de la ciudadanía estuviera depositada en las encuestas, de los cuales los mediadores serían los centros de estudios dedicados a su elaboración. Este elemento sería la principal herramienta de influencia en la política del país: un diagnóstico de las preferencias de los chilenos condicionadas al enfoque, preguntas, temporalidad y agenda de las mismas instituciones.

\footnotetext{
95 Méndez, op. cit.

96 “Eduardo Hamuy y Roberto Méndez: 'El gran enigma de las encuestas políticas es la mujer". Cosas, №320, Santiago, 5 de enero de 1989, p. 45.

${ }^{97}$ Ibid.

98 Álamos, Cecilia, "Elección 89: ya partió la carrera”. El Mercurio, Santiago, 23 de octubre de 1988, p. D8.
} 


\section{¿Por qué ganó el NO? La consolidación de un diagnóstico}

Una vez superada la crítica a las encuestas, vino un período de reflexión. ¿Por qué ganó el NO? Esa era la pregunta común en el oficialismo, todavía afectado por la derrota. En esto, el CEP organizó distintos seminarios donde reflexionaría sobre lo sucedido. Uno de estos sería abierto al público, mientras que el segundo tendría carácter reservado. En ambos se resaltaría el diagnóstico que el CEP había desarrollado sobre el plebiscito, uno no tomado en cuenta por la derecha tradicional. La consecuencia de estos seminarios fue que la producción de estudios de opinión y el mismo CEP pasaría a constituirse como una institución con un conocimiento atractivo para la élite civil de la derecha chilena, incluso para el régimen militar, que antes -al menos indirectamente- había criticado su trabajo. Fue a raíz del resultado del plebiscito que se dividió el espectro entre algunas pocas encuestas fiables y una gran masa que no lo eran. Gracias a sus resultados, la encuesta CEP integró el primer grupo, consolidándose en el espacio público como una fuente de información relevante para la política nacional. Es decir, la instancia mostró el rol de proveedor de diagnósticos que el CEP lograría con sus encuestas.

En el primer seminario del CEP luego del plebiscito participaron Roberto Méndez, Óscar Godoy, Enrique Barros y Arturo Fontaine, estando en el rol de moderador Eliodoro Matte Larraín. Si bien era abierto, participaron una serie de figuras importantes del mundo político y económico de la época. Lo primero que se debía explicar era por qué, habiendo un virtual empate en julio de 1988, en octubre el plebiscito había dado una victoria contundente al NO. Sobre esto, Fontaine Talavera explicaba que la franja televisiva había sido el principal factor de este cambio radical. ${ }^{99}$ Según la encuesta CEP, la franja televisiva del NO, centrada en conceptos como la alegría y esperanza resultaron atractivas para la población, ya que mostraban un mensaje de unidad hacia el futuro, ofreciendo un porvenir mejor, cosa que la campaña del sí no realizaba. El $62 \%$ de la población contestaba que la propaganda política de la oposición era entretenida, mientras que un $19 \%$ decía lo mismo del Sí. El 58\% creía que era motivador lo realizado por el NO, y tan solo un $21 \%$ creía igual cosa para el Sí. ${ }^{100}$ Así el director del CEP destacaba el fracaso de la opción oficialista, recordando que el mismo CEP había dado los lineamientos que cada campaña debería haber explotado para ganar adeptos, pero, según lo evidenciado, esto no había sido tomado en cuenta por el oficialismo. ${ }^{101}$

Aquello se complementaba con lo mencionado por Roberto Méndez al comentar los resultados de las encuestas. Para él, la franja fue tan importante que logró cambiar la opinión

\footnotetext{
99 Es necesario mencionar que la franja fue esencial en la victoria del NO, pero esto no se habría hecho sin "los cambios estructurales y el liderazgo de los partidos y de las organizaciones sociales" que se desarrollaron durante la década de 1980. Véase Huneeus, Carlos. 2014. La democracia semisoberana. Chile después de Pinochet, Santiago, Taurus, p. 90.

100 "Encuesta del CEP desata autocríticas en la derecha". La Época, Santiago, 13 de octubre de 1988.

101 "La influencia de la Tv será decisiva en decisión política”. La Época, Santiago, 13 de octubre de 1988.
} 
en tres grupos que antes beneficiaban al Sí, como eran las mujeres, los electores de provincias y las personas de bajos recursos. ${ }^{102}$ Esta interpretación proveniente del CEP se volvió común en los medios de comunicación, siendo compartida tanto por medios de oposición como por el oficialismo.

El director del Instituto de Ciencia Política de la PUC, Óscar Godoy, analizó la encuesta del CEP, apuntando a una serie de temas y propuestas. Sobre el fracaso del Sí, explicó que fue la televisión, el excesivo uso del anticomunismo, el errado foco en la figura de Pinochet antes que, en la institucionalidad, y la baja aceptación de la población a las modernizaciones, eran elementos que explicaban la derrota electoral. Además, Godoy se mostró preocupado por el poco aprecio dentro de la derecha por el sistema democrático, ya que explicaba que solo un tres por ciento de los adherentes del sí votaron específicamente por este. ${ }^{103}$ La derecha privilegiaba otras cosas como el orden, la estabilidad y el progreso material antes que la democracia. Ante esto, Godoy hizo un llamado importante para el futuro, el "separar el marco de libertades económicas y públicas del modelo autoritario".${ }^{104}$ Es decir, la confianza en que el sistema de libre mercado y estabilidad política podría continuar en democracia. La comunicación de esto al empresariado en el seminario era un llamado a que valorasen la democracia venidera, que se unieran al proceso electoral y que trabajaran por sus ideas en un sistema político pluralista y competitivo, no al amparo de una dictadura. Así, se podría vincular y legitimar el modelo económico en la futura democracia.

Enrique Barros fue uno de los más críticos durante el seminario del 10 de octubre de 1988, aunque recalcaba que luego del plebiscito se vivía un clima de "consenso". Lo que se venía para la derecha no era menor en este punto, ya que él desafiaba a este sector a "recuperar los valores clásicos y a establecer sistemas de comunicación con el electorado". ${ }^{105}$ Debía volver "al honor y la decencia", acostumbrándose "al juego limpio y a la competitividad equilibrada en política". ${ }^{106}$ Ambas cosas se hablaron en esta campaña plebiscitaria, en donde la distancia con el electorado era evidente a la luz de los resultados. Sobre los valores clásicos que debía recuperar la derecha también se avizoraba una crítica del momento, especialmente a lo referente a Pinochet por sus 15 años de gobierno. Lo desarrollado en los últimos años había distanciado a la derecha de la democracia y sus dinámicas, por lo que era necesario recuperarlos para el nuevo periodo que se aproximaba.

\footnotetext{
102 “Mujeres, provincianos y pobres decidieron el plebiscito". Las Últimas Noticias, Santiago, 12 de octubre de 1988.

103 "Régimen ha sufrido una crisis sobre su imagen y capacidad de gobernar". La Época, Santiago, 13 de octubre de 1988.

104 Ibid.

105 Ibid.

106 “Los límites a la evaluación de una derrota”. La Época, Santiago, 13 de octubre de 1988.
} 
Pero también entregaba un diagnóstico político de la situación de aquel momento. Enrique Barros comentaba que la supervivencia del modelo económico e institucional desarrollado por el régimen militar iba a ser duramente cuestionado por la oposición que, si es que vencía en la elección venidera, iba a tratar de reemplazarlo, ya que carecía de legitimidad ante sus ojos. Barros comentaba que esto era un hecho, y que la derecha debía prepararse para ello, tratando de que "este cambio fuera gradual y consentido". ${ }^{107}$ En suma, la derecha debía utilizar los instrumentos de influencia y poder que le eran propios para intentar que este acuerdo fuera lo más lento y gradual posible.

Las reacciones de los asistentes al seminario fueron el resultado de la incertidumbre ante lo que se venía. Juan Ariztía, destacado empresario avícola, sugería que la actitud de conciliación de la oposición no era más que una ardid para engañar a la población. ${ }^{108}$ Sergio Diez, quien también reconocía la equivocación de la propaganda del sí, acusaba a los opositores de "utópicos" y que "era fácil manipular este elemento por medio de la televisión". ${ }^{109}$ Ernesto Ayala, por su parte, creía que la derrota se debía a que: "este no era un país cuerdo". ${ }^{110}$ Esta crítica era rechazada por el oficialismo, ya que a su parecer fomentaba inestabilidad ante posibles inversiones extranjeras: “¿Cómo pretende que la inversión interna y externa no se espante, si él, uno de los líderes empresariales, sostiene que este es un país de locos?". ${ }^{111}$ Según Óscar Godoy, otros actores más vinculados al régimen que estaban presentes, ante la ofuscación por los resultados, sugerían de lleno la necesidad de que Pinochet realizara un nuevo golpe militar. ${ }^{112}$ Así también se comentaba que había sido un error estratégico hacer una franja televisiva, porque permitió que la política volviera como un espectáculo. ${ }^{113}$ Se criticaban así, incluso, a las garantías electorales que tenía el plebiscito. La desazón por la derrota daba paso a la incomprensión de esta, todavía desconfiando de la oposición y el proyecto político que vendría. Según lo anterior, parece ser que algunos empresarios no estaban convencidos del

\footnotetext{
107 Enrique Barros en el seminario ¿Por qué ganó el NO?, 10 de octubre de 1988. 1:17:00 a 1:18:00. Disponible en https://www.cepchile.cl/cep/site/artic/20180913/asocfile/20180913130013/aua_1988_10_10_porque_gano_el_n o_roberto_mendez_enrique_barros_oscar_godoy_arturo_fontaine.mp3 [Fecha de consulta: 6 de septiembre de 2019]

108 "Encuesta del CEP desata autocríticas en la derecha". La Época, Santiago, 13 de octubre de 1988. 109 Ibid.

110 Ibid.

111 “Aquí, cazaculpables”. Qué Pasa, № 916, semana del 20 al 26 de octubre, 1988, p. 10.

112 Entrevista realizada por el autor a Óscar Godoy el 22 de mayo de 2018.

113 Arturo Fontaine Talavera en el seminario ¿Por qué ganó el NO?, 10 de octubre de 1988, 2:10.00-2:11:00. Disponible https://www.cepchile.cl/cep/site/artic/20180913/asocfile/20180913130013/aua_1988_10_10_porque_gano_el_n o_roberto_mendez_enrique_barros_oscar_godoy_arturo_fontaine.mp3 [Fecha de consulta: 6 de septiembre de 2019]
} 
clima de consenso, algo que iba en contraposición a lo que el CEP promovía de cara a las elecciones presidenciales de 1989.

También existió otro seminario, que por su carácter privado no dejó rastros de lo debatido, más allá de la misma realización de este. Este tendría una extensión mayor, ya que se realizó el día 14 de octubre de 1988 con una duración de más de siete horas. Allí, por invitación de Eliodoro Matte, se convocó a una cuarentena de personalidades vinculadas al gobierno, el mundo empresarial, académicos y periodistas de la centroderecha civil, con el objetivo de evaluar y proyectar lo que se vendría para este sector. ${ }^{114}$ En la sesión expondrían primero Óscar Godoy, Roberto Méndez, el economista del Banco Central Jorge Desormeaux y Enrique Barros, dando a conocer su opinión sobre la realidad chilena. Se trataba un caso evidente de relación directa del CEP con las más altas esferas de poder de la derecha civil.

En suma, las encuestas del plebiscito fueron una fuente de información útil para la élite chilena, vinculada especialmente a la institución. Ante el plebiscito, el CEP estaba presente en el campo de la derecha, pero sus insumos en la coyuntura electoral no fueron considerados por el sector. Incluso, durante 1988, el Centro se vio cuestionado por otras encuestadoras vinculadas al oficialismo que daban resultados exageradamente favorables al régimen, probablemente, confundiendo la realidad con un anhelo. Los resultados que entregaba el Centro eran utilizados en forma diferente por los medios de comunicación, la prensa tradicional recogía con mayor interés las publicaciones del Centro, lo que hace pensar la existencia de un circuito comunicacional, mientras que la oposición tenía una recepción mucho menor de la información entregada por la institución. Solo gracias a los buenos resultados del plebiscito el think tank llegaría a transformarse en una caja de herramientas de la política que daría forma a la transición, debido a sus buenos resultados. De este modo, el Centro superó un desafío importante como era el plebiscito de 1988, dando resultados confiables para todo el espectro político del país. Fue una victoria en su afán de posicionarse como una institución independiente y referente de todo el espectro político chileno, obteniendo mayor influencia en el espacio público.

\section{Conclusión}

A lo largo del texto, hemos visto cómo fue valorada la información proveída por el Centro de Estudios Públicos en los medios de comunicación. Se ha explicado que el CEP creó las encuestas con el fin de comprender el impacto que las reformas económicas tuvieron en las personas,

\footnotetext{
114 “Analizaron situación del país tras el plebiscito". El Mercurio, Santiago, 15 de octubre de 1988, p. C3. En el medio se consignó la presencia de: Arturo Alessandri Besa, Andrés Allamand, Sergio Baeza, Enrique Barros, Carlos Cáceres, Jorge Carey, Gastón Cummins, Raúl de la Fuente, Sergio Diez, Jorge Desormeaux, Manuel Feliú, Arturo Fontaine Talavera, David Gallagher, Óscar Godoy, José Luis Ibáñez, Pedro Ibáñez Ojeda, Juan Pablo Illanes, Fernando Léniz, Hernán Larraín, Evelyn Matthei, Carlos Martínez Sotomayor, Roberto Méndez, Fernando Moreno, José Musalem, Sebastián Piñera, Ricardo Rivadeneira, Lucía Santa Cruz, Carlos Urenda, Jorge Yarur y Cristián Zegers.
} 
camino al plebiscito de 1988. En ese sentido, fue pionera en la derecha del país por entregar encuestas dedicadas al análisis político, económico y social cuyo fin era la liberación total de sus datos. Desde su creación en adelante, la encuesta tuvo un tibio recibimiento en los medios de comunicación, aunque se constató un aumento importante en las menciones que la institución tuvo en diferentes diarios, siendo mayormente aquellos vinculados al grupo Edwards sus principales difusores. Salvo por aquella vinculación mediática, el Centro fue una encuestadora entre otras en el periodo previo a la coyuntura plebiscitaria, entregando información muchas veces alarmante para la derecha, en contraposición de otras encuestas cercanas al régimen. Es decir, el Centro estaba inserto en campo comunicacional de las derechas, pero sus diagnósticos no eran especialmente valorados en el espacio público.

A contrario de otras instituciones del sector comprometidas con la opción SÍ, el CEP tampoco participó activamente por la continuidad de Pinochet. A fin de cuentas, lo realizado por la institución buscaba separar el modelo de desarrollo y principios del liberalismo del mismo régimen construyendo una opción autónoma de este, basada en la lógica y lenguaje de la academia. Por aquello, el Centro fue una de las pocas encuestadoras de las derechas que entregó resultados negativos para Pinochet. En un contexto donde entregar datos fiables que mostraran matices era políticamente visto como problemático, ya que en los medios de comunicación de entonces, y especialmente con el descalabro de las encuestadoras de la derecha, se apreció un uso político, incluso, propagandístico de estas.

En este sentido, más allá del acierto del Centro en los datos entregados y la lejanía que tuvo en el plebiscito con la opción Sí, es interesante resaltar la decisión política de mantenerse al margen de la contienda electoral, entregando la información que se obtuviese en sus análisis. Un hecho que en 1988 no era obvio ya que las encuestas vinculadas a la derecha se utilizaron como propaganda política antes que insumos científicos. A su vez, en perspectiva, lo anterior contribuyó a que el mismo Centro fuera valorado por su buen resultado en la coyuntura plebiscitaria, en contraste con el resto de las instituciones que aseguraban a Pinochet su victoria. Posibilitando de este modo una confianza entre la comunidad política y los insumos que el Centro entregaba, útil para que la institución se transformara en un termómetro de la política a partir del retorno a la democracia.

Por último, es interesante mencionar la casi inexistencia de la opinión de políticos sobre las encuestas en el plebiscito de 1988. Al menos respecto a la encuesta CEP, no se encontraron indicios de una valoración de este insumo en la política partidista, al contrario de lo que sucede en la actualidad, donde los políticos responden y se basan en las encuestas. Todavía en esos años las encuestas no jugaban un papel central en la política chilena, algo que cambiaría con las elecciones presidenciales que seguirían al retorno a la democracia. 


\section{Bibliografía}

\section{Prensa}

Economía y Sociedad (Santiago).

El Mercurio (Santiago).

Ercilla (Santiago).

Estrategia (Santiago).

La Época (Santiago).

La Segunda (Santiago).

La Tercera (Santiago).

Qué Pasa (Santiago).

\section{Entrevistas}

Entrevista realizada por el autor a Arturo Fontaine Talavera el 14 de mayo de 2018.

Entrevista realizada por el autor a Arturo Fontaine Talavera el 25 de mayo de 2018.

Entrevista realizada por el autor a Óscar Godoy el 22 de mayo de 2018.

Entrevista realizada por el autor a Roberto Méndez el 27 de junio de 2018.

\section{Bibliografía secundaria}

Arriagada, G. 1998. Por la razón o la fuerza. Chile bajo Pinochet, Santiago, Editorial Sudamericana.

Aylwin, P. 1998, El Reencuentro de los demócratas, Santiago, Ediciones B.

Barrueto, F. y Navia, P. 2015. "Evolución de las preferencias políticas y de políticas públicas entre el sector popular y el resto de la sociedad chilena entre 1990 y 2012", en Perfiles latinoamericanos, vol. 23, n 46, México D. F., México, pp. 61-89.

Brunner, J. J. y Sunkel, G. 1993. Conocimiento, sociedad y política, Santiago, LibrosFLacso.

Cavallo, A. 2008 [1998]. La historia oculta del régimen militar, Chile 1973-1978, Santiago, Uqbar, edición en EPUB.

Contreras, G. y Navia, P. 2013. “Diferencias generacionales en la participación electoral en Chile, 19882010", en Revista de Ciencia Política, vol. 33, n², Santiago, pp. 419-441.

Cordero, R. (ed.). 2009. La sociedad de la opinión. Reflexiones sobre encuestas y cambio político en democracia, Santiago, Ediciones Universidad Diego Portales, pp. 197-224.

Cordero, R. 2009. "Dígalo con números: la industria de la opinión pública en Chile”, en Cordero, R. (ed.), La sociedad de la opinión. Reflexiones sobre encuestas y cambio político en democracia, Santiago, Ediciones Universidad Diego Portales, pp. 69-94.

Dammere, L. 2009. “¿Falsa alarma? Temor, crimen y opinión pública en Chile”, en Cordero, R. (ed.), La sociedad de la opinión. Reflexiones sobre encuestas y cambio político en democracia, Santiago, Ediciones Universidad Diego Portales, pp. 225-250.

Dockendorff, A. 2010. "El rol de las encuestas en las elecciones de 2005. Selección de candidatos presidenciales en Chile”, en Revista Enfoques. Ciencia Política y Administración pública, vol. VIII, $\mathrm{n}^{\circ}$ 13, Santiago, pp. 159-180.

Fermandois, J. 1991. "De una inserción internacional a otra. Política exterior de Chile, 1966-1991", en Estudios Internacionales $n^{\circ} 96$, Santiago, 433-455.

Fermandois, J. 2005. Mundo y fin de mundo. Chile en la política mundial 1900-2004, Santiago, Ediciones Universidad Católica. 
Fermandois, J. y Soto, A. 2007. "El plebiscito de 1988. Candidato único y competencia”, en San Francisco, A. y Soto, A. (eds.), Camino a La Moneda. Las elecciones presidenciales en la historia de Chile, Santiago, Centro de Estudios Bicentenario-Instituto de Historia, Pontificia Universidad Católica de Chile, pp. 371-399.

Ffrench-Davis, R. 2018. Reformas económicas en Chile, 1973-2017. Neoliberalismo, crecimiento con equidad, inclusión, Santiago, Taurus.

Fontaine Aldunate, A. 1988. Los economistas y el general Pinochet, Santiago, Zigzag.

Fontaine Talavera, A. 1992. "Sobre el pecado original de la transformación capitalista", en Levine, Barry B, El desafío neoliberal. El fin del tercermundismo en América Latina, Bogotá, Norma, pp. 93-139.

Gálvez, L. 2011. "Las encuestas electorales y el debate sobre su influencia en las elecciones”, en Revista Mexicana de Opinión Pública 11, México D. F., México, pp. 25- 43.

Gárate, M. 2014. La revolución capitalista de Chile (1973-2003), Santiago, Universidad Alberto Hurtado.

Huneeus, C. 1985. "La apertura política y sus implicancias", en Revista de Ciencia Política, vol. VII, 1, Santiago, pp. 25-84.

Huneeus, C. 1999. "Las encuestas de opinión en las nuevas democracias en América Latina", en Contribuciones $n^{\circ}$ 9, pp. 9-30.

Huneeus, C. 2009. "Las encuestas de opinión pública en las nuevas democracias de América Latina", en La sociología en sus escenarios n 9, Medellín, Colombia, pp. 9-29.

Huneeus, C. 2014. La democracia semisoberana. Chile después de Pinochet, Santiago, Taurus.

Huneeus, C. 2016. El Régimen de Pinochet, Santiago, Taurus.

Jara Barrera, M. 2019. "El origen del Centro de Estudios Públicos: importando el liberalismo para una transición ideológica, 1980-1982", en Historia 396 n² 1, Valparaíso, pp. 225-253.

Kavanagh, D. 1994. “Las encuestas de opinión pública”, en Estudios Públicos 53, Santiago, pp. 145-170. Meller, P. 1998. Un siglo de política económica en Chile (1890-1990), Santiago, Editorial Andrés Bello.

Mönckeberg, M. O. 2013. Los magnates de la prensa. Concentración de los medios de comunicación en Chile, Santiago, Debolsillo.

Morales Martín, J. J. 2018. “Dominación filantrópica y gobernabilidad democrática: el caso de la Fundación Ford y CIEPLAN en Chile (1976-1990)", en Historia, vol. 51, n 1, Santiago, pp. 141-153.

Muñoz, H. 1986. La política exterior del gobierno militar chileno, Santiago, Ediciones del Ornitorrinco.

Navia, P. y Osorio, R. 2015. “Las encuestas de opinión pública en Chile antes de 1973”, en Latin American Research Review 30, Pittsburgh, pp. 117-139.

Paley, J. 2001. "Making Democracy Count: Opinion Polls and Market Surveys in the Chilean Political Transition", en Cultural Anthropology vol. 16, n², California, EE. UU., pp. 135-164.

Portales, C. 1993. "Los factores externos y el régimen autoritario", en Drake, P., y Jaksic, I. (eds.). El difícil camino hacia la democracia 1982-1990, Santiago, FLACSO.

Rosanvallon, P. 2003. Por una historia conceptual de lo político, Buenos Aires, Fondo de Cultura Económica.

Rubio Apiolaza, P. 2012. Los civiles de Pinochet. La derecha en el régimen militar chileno, 1983-1990, Santiago, DIBAM.

Rubio Apiolaza, P. 2019. "Los Estados Unidos y la transición a la democracia en Chile: lecturas e influencias entre 1985 y 1988", en Documentos de Trabajo IELAT n 120, España, pp. 1-56.

San Francisco, A. "La elección presidencial de 1970. Sesenta días que conmovieron a Chile (y al mundo)", en San Francisco, A. y Soto, A. (eds), Camino a La Moneda. Las elecciones presidenciales en la historia de Chile, Santiago, Centro de Estudios Bicentenario-Instituto de Historia, Pontificia Universidad Católica de Chile, pp. 333-370. 